PLOS ONE

\title{
Production, Reproduction and Adaptation characteristics of Boran cattle breed under changing climate: A systematic review and meta-analysis \\ --Manuscript Draft--
}

\begin{tabular}{|c|c|}
\hline Manuscript Number: & PONE-D-20-39503 \\
\hline Article Type: & Research Article \\
\hline Full Title: & $\begin{array}{l}\text { Production, Reproduction and Adaptation characteristics of Boran cattle breed under } \\
\text { changing climate: A systematic review and meta-analysis }\end{array}$ \\
\hline Short Title: & $\begin{array}{l}\text { Production, Reproduction and Adaptation characteristics of Boran cattle: A systematic } \\
\text { review and meta-analysis }\end{array}$ \\
\hline Corresponding Author: & $\begin{array}{l}\text { Merga Bayssa, Ph.D. } \\
\text { Hawassa University College of Agriculture } \\
\text { Hawassa, Sidama Regional State ETHIOPIA }\end{array}$ \\
\hline Keywords: & Adaptation, Boran cattle, Climate change, Genetic correlation, Heritability \\
\hline Abstract: & 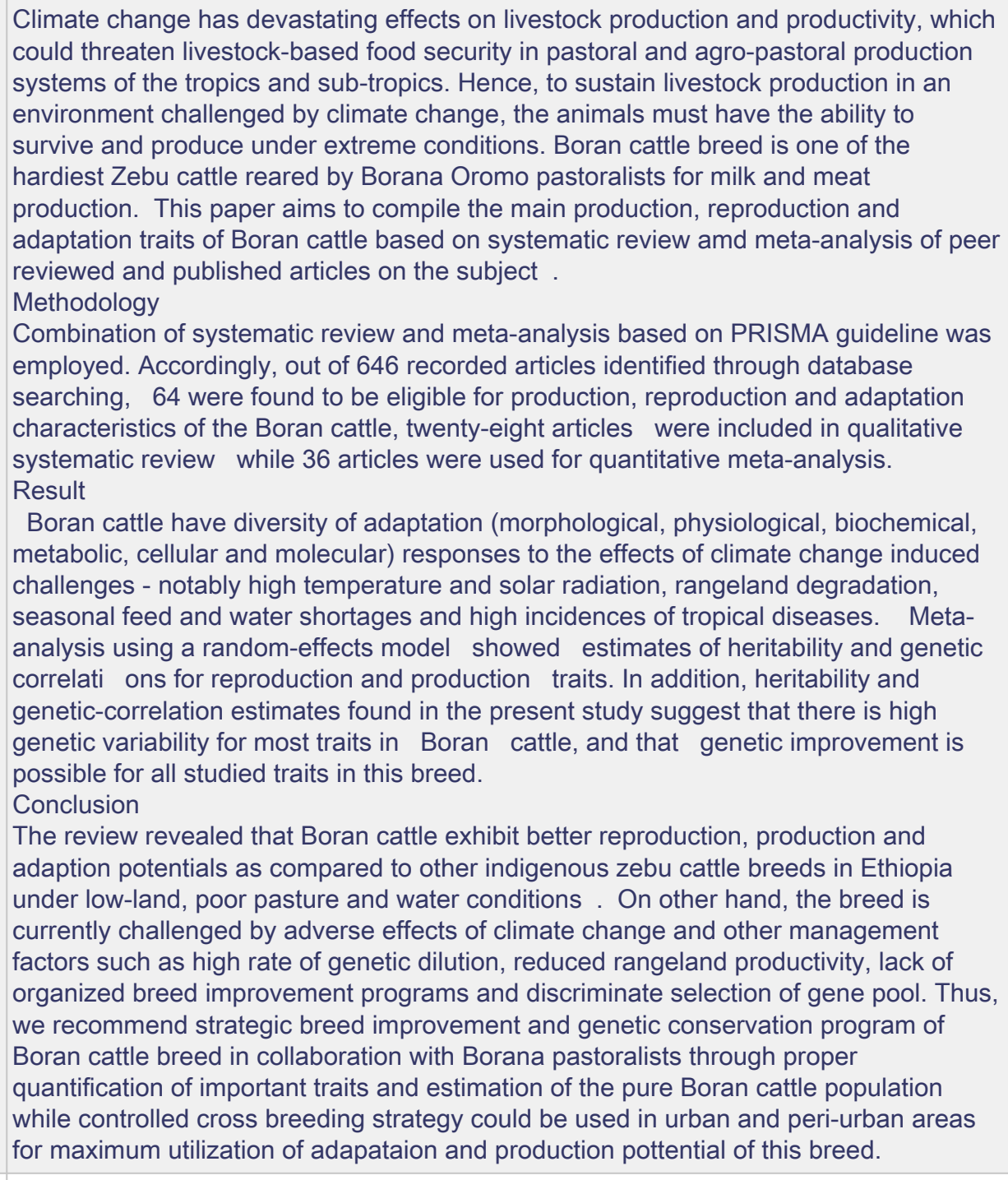 \\
\hline \multirow[t]{4}{*}{ Order of Authors: } & Merga Bayssa, Ph.D. \\
\hline & Sintayehu Yigrem \\
\hline & Simret Betsha \\
\hline & Adugna Tolera, Ph.D., Professor \\
\hline
\end{tabular}




\section{Additional Information:}

Question

\section{Response}

\section{Financial Disclosure}

Enter a financial disclosure statement that describes the sources of funding for the work included in this submission. Review the submission guidelines for detailed requirements. View published research articles from PLOS ONE for specific examples.

This statement is required for submission and will appear in the published article if the submission is accepted. Please make sure it is accurate.

\section{Unfunded studies}

Enter: The author(s) received no specific funding for this work.

\section{Funded studies}

Enter a statement with the following details:

- Initials of the authors who received each award

- Grant numbers awarded to each author

- The full name of each funder

- URL of each funder website

- Did the sponsors or funders play any role in the study design, data collection and analysis, decision to publish, or preparation of the manuscript?

- NO - Include this sentence at the end of your statement: The funders had no role in study design, data collection and analysis, decision to publish, or preparation of the manuscript.

- YES - Specify the role(s) played.

* typeset

\section{Competing Interests}

Use the instructions below to enter a competing interest statement for this submission. On behalf of all authors, disclose any competing interests that could be perceived to bias this work-acknowledging all financial support and any other relevant financial or nonfinancial competing interests.
No, The funders had no role in study design, data collection and analysis, decision to publish, or preparation of the manuscript. e 
This statement will appear in the published article if the submission is accepted. Please make sure it is accurate. View published research articles from PLOS ONE for specific examples.

\section{NO authors have competing interests}

Enter: The authors have declared that no competing interests exist.

\section{Authors with competing interests}

Enter competing interest details beginning with this statement:

I have read the journal's policy and the authors of this manuscript have the following competing interests: [insert competing interests here]

\section{* typeset}

\section{Ethics Statement}

Enter an ethics statement for this submission. This statement is required if the study involved:

- Human participants

- Human specimens or tissue

- Vertebrate animals or cephalopods

- Vertebrate embryos or tissues

- Field research

Write "N/A" if the submission does not require an ethics statement.

General guidance is provided below.

Consult the submission guidelines for detailed instructions. Make sure that all information entered here is included in the Methods section of the manuscript. 


\section{Format for specific study types}

Human Subject Research (involving human participants and/or tissue)

- Give the name of the institutional review board or ethics committee that approved the study

- Include the approval number and/or a statement indicating approval of this research

- Indicate the form of consent obtained (written/oral) or the reason that consent was not obtained (e.g. the data were analyzed anonymously)

\section{Animal Research (involving vertebrate}

\section{animals, embryos or tissues)}

- Provide the name of the Institutional Animal Care and Use Committee (IACUC) or other relevant ethics board that reviewed the study protocol, and indicate whether they approved this research or granted a formal waiver of ethical approval

- Include an approval number if one was obtained

- If the study involved non-human primates, add additional details about animal welfare and steps taken to ameliorate suffering

- If anesthesia, euthanasia, or any kind of animal sacrifice is part of the study, include briefly which substances and/or methods were applied

\section{Field Research}

Include the following details if this study involves the collection of plant, animal, or other materials from a natural setting:

- Field permit number

- Name of the institution or relevant body that granted permission

\section{Data Availability}

Yes - all data are fully available without restriction

Authors are required to make all data underlying the findings described fully available, without restriction, and from the time of publication. PLOS allows rare exceptions to address legal and ethical concerns. See the PLOS Data Policy and FAQ for detailed information. 
A Data Availability Statement describing where the data can be found is required at submission. Your answers to this question constitute the Data Availability Statement and will be published in the article, if accepted.

Important: Stating 'data available on request from the author' is not sufficient. If your data are only available upon request, select 'No' for the first question and explain your exceptional situation in the text box.

Do the authors confirm that all data underlying the findings described in their manuscript are fully available without restriction?

Describe where the data may be found in All relevant data are within the manuscript and its Supporting Information files. full sentences. If you are copying our sample text, replace any instances of $X X X$ with the appropriate details.

- If the data are held or will be held in a public repository, include URLs, accession numbers or DOls. If this information will only be available after acceptance, indicate this by ticking the box below. For example: $A$ II $X X X$ files are available from the $X X X$ database (accession number(s) $X X X, X X X$.).

- If the data are all contained within the manuscript and/or Supporting Information files, enter the following: All relevant data are within the manuscript and its Supporting Information files.

- If neither of these applies but you are able to provide details of access elsewhere, with or without limitations, please do so. For example:

Data cannot be shared publicly because of $[X X X]$. Data are available from the $X X X$ Institutional Data Access / Ethics Committee (contact via $X X X)$ for researchers who meet the criteria for access to confidential data.

The data underlying the results presented in the study are available from (include the name of the third party 
and contact information or URL).

- This text is appropriate if the data are owned by a third party and authors do not have permission to share the data.

* typeset

Additional data availability information:

Tick here if the URLs/accession numbers/DOls will be available only after acceptance of the manuscript for publication so that we can ensure their inclusion before publication. 
1 Production, Reproduction and Adaptation characteristics of Boran cattle breed under 2 changing climate: A systematic review and meta-analysis

3 Merga Bayssa, Sintayehu Yigrem and Simret Betsa, Adugna Tolera

4 Hawassa University, College of Agriculture, P.o. Box 5, Hawassa, Ethiopia

$6 \quad$ Corresponding author Email: mergabayssa@yahoo.com

7

8 Abstract

9 Introduction

10

11

12

13

14

15

16

17

18

\section{Methodology}

\section{Result}

Climate change has devastating effects on livestock production and productivity, which could threaten livestock-based food security in pastoral and agro-pastoral production systems of the tropics and sub-tropics. Hence, to sustain livestock production in an environment challenged by climate change, the animals must have the ability to survive and produce under extreme conditions. Boran cattle breed is one of the hardiest Zebu cattle reared by Borana Oromo pastoralists for milk and meat production. This paper aims to compile the main production, reproduction and adaptation traits of Boran cattle based on systematic review amd meta-analysis of peer reviewed and published articles on the subject.

Combination of systematic review and meta-analysis based on PRISMA_guideline was employed. Accordingly, out of 646 recorded articles identified through database searching, 64 were found to be eligible for production, reproduction and adaptation characteristics of the Boran cattle, twentyeight articles were included in qualitative systematic review while 36 articles were used for quantitative meta-analysis.

Boran cattle have diversity of adaptation (morphological, physiological, biochemical, metabolic, cellular and molecular) responses to the effects of climate change induced challenges - notably 
high temperature and solar radiation, rangeland degradation, seasonal feed and water shortages

28 and high incidences of tropical diseases. Meta-analysis using a random-effects model showed estimates of heritability and genetic correlations for reproduction and production traits. In addition, heritability and genetic-correlation estimates found in the present study suggest that there is high genetic variability for most traits in Boran cattle, and that genetic improvement is possible for all studied traits in this breed.

\section{Conclusion}

The review revealed that Boran cattle exhibit better reproduction, production and adaption potentials as compared to other indigenous zebu cattle breeds in Ethiopia under low-land, poor pasture and water conditions. On other hand, the breed is currently challenged by adverse effects of climate change and other management factors such as high rate of genetic dilution, reduced rangeland productivity, lack of organized breed improvement programs and discriminate selection of gene pool. Thus, we recommend strategic breed improvement and genetic conservation program of Boran cattle breed in collaboration with Borana pastoralists through proper quantification of important traits and estimation of the pure Boran cattle population while controlled cross breeding strategy could be used in urban and peri-urban areas for maximum utilization of adapataion and production pottential of this breed.

KEY WORDS: Adaptation, Boran cattle, Climate change, Genetic correlation, Heritability

45

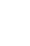

\section{Introduction}

Most developing countries have been facing severe poverty due to the devastating effects of the climate change on the agriculture and food production systems. Like other agricultural sectors, climate change also adversely impacts the livestock sector. Among the livestock sector, cattle are one of the most susceptible species to the effects of climate change [1]. Thus, livestock-based food security and livelihood is being threatened in many parts of the world including Ethiopia. Recurrent drought, feed and water scarcity and endemic tropical diseases are the major factors which negatively influence livestock production in the east African rangelands [2]. Hence, it is critical to identify agro-ecological specific climate resilient adaptive animals to sustain livestock 
production. Ethiopia is endowed with diverse livestock genetic resources due to variable agroecology and geographical proximity to the centre of livestock domestication [3].

57 The Boran cattle breed, categorized as Bos indicus (humped Large East African Shorthorn Zebu type) is one of the local cattle breeds from the Borana range lands in the southern Ethiopia reared by the Borana pastoralits of Oromoo people for meat and milk production. They have their origin in Ethiopia and were initially introduced into Kenya by Ethiopian Boran pastoralists from the southern Ethiopia (2). The animals possess several adaptive mechanisms which are helpful for their survival in harsh environmental conditions. Adaptive characteristics to warm climates encompass a wide range of physiological functions, behavioural and morphological attributes. The Boran cattle have special merits of surviving, producing and reproducing under high ambient temperature, seasonal fluctuations in feed supply and quality, water shortage and high diseases incidence including tick infestations [4,5]. In addition, they are noted for their docility, high fertility, early maturity and ability to walk long distances in search of feed and water than most other B. indicus breeds [2].

Boran cattle are very versatile and well adapted to arid and semi-arid environments. The cows are very efficient converters of pasture forage into body fat deposits, which are later, mobilized during periods of feed scarcity and lactation. The cows therefore hardly lose body conditions during lactation or slight droughts [6]. However, declining feed availability and quality due to increasing population pressure, land use change, rangeland degradation, bush encroachment and climate change are posing serious challenges to livestock productivity in the Borana lowlands. In addition, Ethiopian Boran cattle breed is under threat due to several factors such as recurrent drought, lack of systematic selection and breeding programs and dilution with other breeds [7]. There is limited comprehenssive information on production, reproduction and adaption traits of Boran cattle breed in the lowlands of Borana rangelands. Furthermore, the Boran breed is under threat from genetic erosion due to the admixture of other breeds that are used for restocking after drought [1]. Therefore, the current review provides an overview of efforts made to summarize production, reproduction and adaptation traits of Boran cattle and major challenges for Boran cattle breed improvement and conservation programmes in the pastoral and agro-pastoral production systems of Borana lowlands. 


\section{Materials and Methods}

\subsection{Scope of studies and Evaluated traits}

87 We conducted a combination of systematic and meta-reviews as the methodology of qualitative comparative analysis (QCA). To do this, we used the actual published studies as our data (rather than the data used by each study), and this enabled us to pool non-standardized and qualitative information[8] for adaptation traits while for production and reproduction parameters[5] quantitative parameters were pooled to obtain estimated mean values. The implementation of the systematic and meta-reviews followed the Preferred Reporting Items for Systematic Reviews and Meta-Analyses (PRISMA) guideline [9] and the checklist used to ensure inclusion of relevant information (Figure1). These include (1) characterization of the research question, namely "what are main production, reproduction and adaptation characteristics of Ethiopian Boran cattle breed as compared to other zebu cattle in the country?", (2) web-based literature retrieval of relevant journals and case studies (3) selection of relevant studies by scanning the abstracts and titles of

(4) abstraction of information from selected sets of final articles (5) determination of quality of the information available in these articles (6) evaluation of the extent of heterogeneity of the articles $[9,10]$. The outcomes of interest were production, reproduction and adaptation characteristics of Boran cattle breed and the questions addressed were the following: (i) number, diversity, and scope of studies carried out so far, (ii) heterogeneities of estimates, (iii) pooled weighted mean estimates, and (iv) factors associated with the production, reproduction and adaptation characteristics of Boran cattle breed.

\subsection{Search and selection of studies}

106

107

108

109

110

111

112

113

114

We used data basis from AGORA, SCOPUS, Google Scholar, Google web, PubMed, Science Direct, $\mathrm{CAB}$ direct, African Journals online (AJOL) and lists of references of articles from peer reviewed publications. The language of publications was restricted to English. The key words utilized for electronic searches were: 'growth AND meat production AND Boran cattle', Milk production AND Boran cattle breed', 'Reproduction AND Boran cattle breed and Adaptation AND Boran cattle breed'. The last search was done on December 15, 2019. Eligible studies were selected by using inclusion and exclusion criteria. A study was eligible if it fulfilled the following criteria: (i) full text and published in English (ii) carried out on Boran cattle breed and published before December 15, 2019, (iii) cross-sectional/ longitudinal/case control studies, (iv) relevant response 
variables of production, reproduction and adaptation traits. In the succeeding steps, reviews, case reports, studies carried out before 1985 and unavailable papers were excluded, and full text reports were screened for eligibility. Exclusion of screened reports was done by the following criteria: duplication (articles/data), only conducted on cross breeds (to reduce bias/ method related heterogeneity), unpublished organization reports, sample size (<50 records in animal studies), and inconsistent data (data incoherent within a table or tables or in the narrative sections, and could not be figured out).

\subsection{Data Extraction and Variable transformation}

The following data were extracted from eligible studies: first author, year of publication, year of study, country, sample size (herd size/records), sampling methods (probability/nonprobability based), breed (Boran, crosses/other zebu breeds) and study traits (production, reproduction and adaptation traits). For adaptation traits relevant information on morphological, behavioural, physiological, neuro-endocrine, blood biochemical and metabolic and molecular responses related to heat stress, water and feed scarcity and challenges of tropical diseases were gathered. For reproduction and production traits information on direct and maternal heritability, genetic correlations among traits and published standard errors for the relevant parameter estimates were included. Other information recorded were journal and database name, number of records, years of data collection, phenotypic mean and standard deviation, and the used estimation method (REML or Bayesian). When the same estimate was reported in different publications, based on the same database, only the most recent publication was included in the analysis. Besides that, metaanalysis was executed only for traits in which the estimates were based on at least two different databases, to minimize the possible impact of non-independence among articles. For articles in which the standard error for the heritability or correlation estimates were not reported, approximated standard errors were derived by using the combined-variance method [11] which is given as:

$\mathrm{SE}_{\mathrm{ij}}=\sqrt{ }\left(\left(\sum_{k=1}^{k} s^{2} i k n^{2} \mathrm{ik} / \sum_{k=1}^{k} \mathrm{nik}\right) / \mathrm{nij}\right)$

Where $\mathrm{SE}_{\mathrm{ij}}$ is the predicted standard error for published parameters estimate for the $\mathrm{i}^{\text {th }}$ trait in the

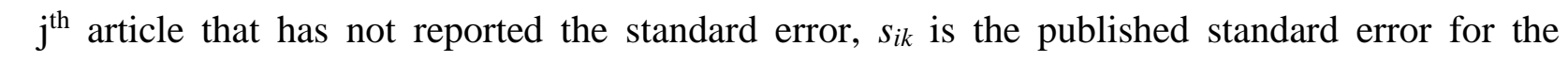
parameter estimate for the $\mathrm{i}^{\text {th }}$ trait in $\mathrm{k}^{\text {th }}$ article that has reported the standard error, nik is the number 
144 of used records to predict the published parameter estimate for the $\mathrm{i}^{\text {th }}$ trait in the $\mathrm{k}^{\text {th }}$ article that has 145 reported standard error, and $n_{i j}$ is the number of used records to predict the published parameter estimate for the $\mathrm{j}^{\text {th }}$ article that has not recorded standard error. Since published correlations don't have normal distribution, they were converted to the Fisher's $\mathrm{Z}$ scale and all analyses are performed using transformed values. The results, such as the estimated parameter and its confidence interval, would then be back transformed to correlation for presentation [12]. The approximate normal scale based on Fisher's Z transformation [12,13] is as follows:

$\mathrm{Z}_{\mathrm{ij}}=0.5\left[\ln \left(1+\mathrm{r}_{\mathrm{gij}}\right)-\left(\ln \left(1-\mathrm{r}_{\mathrm{gij}}\right)\right]\right.$, where $\mathrm{r}_{\mathrm{gij}}$ is the published genetic correlation estimate for the ith trait in the jth article. To return to the original scale, the following equation [12] was used:

$153 \mathrm{r}_{\text {gij }}^{*}=\left(\mathrm{e}^{2 \mathrm{zij}}-1\right) /\left(\mathrm{e}^{2 \mathrm{zij}}+1\right)$, where rgij is the re-transformed genetic correlation for the $\mathrm{i}^{\text {th }}$ trait in the $154 \mathrm{j}^{\text {th }}$ article andZ $\mathrm{ij}$ isthe Fisher's $\mathrm{Z}$ transformation.

\subsection{Quality control}

Box plots weighted by the number of records were constructed for each trait to identify potential outliers. To ensure the reliability of the meta-analysis, and avoid the estimation of biased estimates, a minimum number of articles required for each $i^{\text {th }}$ trait were obtained through the following relative standard error [14]: $\mathrm{RSE}_{\mathrm{i}}=\left(\left(\mathrm{si} / \bigvee_{\mathrm{ni}}\right) / \mathrm{Xi}\right) * 100$, where $\mathrm{RSEi}$ is the relative standard error, $\mathrm{S}_{\mathrm{i}}$ is the standard deviation estimated from the published parameter estimates for the $\mathrm{i}^{\text {th }}$ trait, $\mathrm{n}_{\mathrm{i}}$ is the number of articles that have reported parameter estimates for the $\mathrm{i}^{\text {th }}$ trait, and $X_{i}$ is the average of parameter estimates for the $i^{\text {th }}$ trait. Traits with a RSE higher than $25 \%$ were discarded.

\subsection{Data Analysis}

Qualitative information on adaptation traits was summarized and tabulated for synthesis while production and reproduction data were analysed by using R software [15].

\subsubsection{Phenotypic trait}

169 Means and standard deviations were calculated for all traits by using the sample sizes as weights.

170 The total number of records for each phenotypic trait was calculated as the sum of number of 171 records in each article that reported the trait. The coefficient of variation in percentage $(\mathrm{CV}(\%))$

172 for each $i^{\text {th }}$ trait was calculated as follows: CV $(\%)=\mathrm{si} / \mathrm{Xi} * 100$, where $s i$ is the standard deviation 173 for the $\mathrm{i}^{\text {th }}$ trait, and $\mathrm{Xi}$ is the trait mean. 


\subsubsection{Heritability and genetic correlation}

Meta-analysis was performed on the basis of a random-effects model [12], in which the parameter estimates for all traits were analysed_by assuming independence and normality.

These assumptions were investigated for each trait by using the Box-Pierce and Shapiro-Wilk tests, available respectively in the box.testand shapiro.testfunctions of the $\mathrm{R}$ software [15]. The metaforpackage [16] available in the R software [15] was used to fit the following random-effects model for each trait: $\tilde{\Theta}_{j}=\tilde{\Theta}+u_{j}+e_{j}$

where $\tilde{\theta} \mathrm{j}$ is the published parameter estimate in the $\mathrm{j}^{\text {th }}$ article, $\tilde{\Theta}$ is the weighted population parameter mean, uj the among study component of the deviation from mean, assumed as $\mathrm{u}_{\mathrm{i}} \sim\left(\mathrm{N}\left(0, \tau^{2}\right)\right.$, where $\tau^{2}$ is the variance representing the amount heterogeneity among the studies, $\mathrm{e}_{\mathrm{j}}$ is with-in study component due to sampling error in the parameter estimate in the jth article, assumed as $\mathrm{e}_{\mathrm{j}} \sim\left(\mathrm{N}\left(0, \sigma_{\mathrm{e}}^{2}\right)\right.$, where $\sigma_{\mathrm{e}}^{2}$ is the with-in variance. The $\mathrm{I}^{2}$ index [17] used to quantify the degree of heterogeneity among studies $\left(\tau^{2}\right)$ for each trait can be described as follows: $I^{2}=\left(\left(Q^{-}\right.\right.$ df)/Q) x100,

\section{Where $\mathrm{Q}$ is the $\mathrm{Q}$ statistics [18] given by}

$\mathrm{Q}=\sum_{k=1}^{k} \mathrm{wi}(\tilde{\Theta} \mathrm{j}-\tilde{\Theta})^{2}$

Where $w_{j}$ is the parameter estimate weight (as the inverse of published sampling variance for the parameter, 1/v) in the $\mathrm{j}^{\text {th }}$ article; ẽrtand $\tilde{\theta}$ were defined above in the random-effects model; and the d.f. is the degrees of freedom ( $\mathrm{J}-1$, where $\mathrm{J}$ is the number of used articles) of a chi-squared distribution assumed for expected $\mathrm{Q}$ value on the assumption that $\tau^{2}=0$. Basically, $\mathrm{I}^{2}$ values estimated as $25 \%, 50 \%$ and $75 \%$ might be considered as low, moderate and high heterogeneity respectively [17]. The $95 \%$ lower and upper limits for the estimated parameter would be computed respectively for each trait as follows:

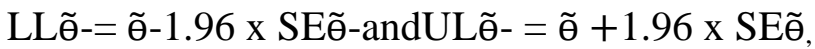

Where SẼ̃is the predicted standard error for the estimated parameter $\Theta$, given by

$\mathrm{SE} \tilde{\Theta}=\left(1 / \sum_{J=1}^{J} \mathrm{wj}.\right)$ 


\section{Results and Discussion}

\subsection{Search and selection of studies}

204

205

206

207

208

209

210

211

212

213

214

215

216

217

218

219

220

221

222

223

Figure 1 presents a flow diagram of the search and selection of studies. A total of 646 reports written in English were identified, of which 618 were original papers, 20 grey literatures and 8 review papers (5 narratives and 3 systematic review on adaptation characteristics). Five hundred ninety-eight original reports were selected after the removal of duplicates.

At screening stage, 321 papers were selected based on the selection criteria of their abstracts, of which 72 articles were subjected to full text assessment for validity. Finally, 64 articles were found to be eligible for adaptation, production and reproduction characteristics for full text exraction whereas 8 articles were excluded for failing to fullfill the selection criteria. Out of these studies, 28 articles were included in qualitative systematic synthesis of adaptation characteristics while 36 articles were used for quantitative meta-reviews of production and reproduction characteristics. The number, diversity and scope of studies carried out so far are inadequate for production and reproduction traits while those on specific and nonspecific adaptation traits of Borana cattle were relatively abundant.

\subsection{Adaptation characteristics of Boran cattle breed}

\subsubsection{Adaptation to harsh environmental conditions}

Table1 shows results of the systematic review of adaptation characteristics of Boran and other zebu cattle breeds in arid and semi-arid regions of the tropics. The focus of the 28 articles reviewed were split into seven categories of adaptation traits, which included morphological (11), behavioural (8), physiological (7), neuro-endocrine (6), blood biochemical (7), metabolic (4) cellular and molecular (9) adaptation traits of Boran and other zebu cattle breeds in the tropics .

Table1. Number and percentages of studies on adaptation responses of Boran and other zebu cattle breeds included the systematic reviews

\begin{tabular}{lcc}
\hline Adaptation traits & Number of studies included & \% of the studies \\
\hline Morphological & 11 & 39.3 \\
Behavioural & 8 & 28.6 \\
Physiological & 7 & 25
\end{tabular}


Neuro-endocrine

Blood biochemical

Metabolic

Cellular and molecular
21.4

25

14.3

32.2
224

225

226

227

228

229

230

231

232

233

234

235

236

237

238

239

240

241

242

243

244

245

246

247

248

Boran cattle breed have tremendous adaptive capacity to harsh environment through specific morphological and physiological characteristics $[6,7,19,20]$. On the other hand, heritability $\left(\mathrm{h}^{2}\right)$ estimates of adaptation traits were not conducted for Boran cattle in this study due to scarcity of published data for the traits. In some tropical cattle breeds heritability estimates for heat tolerance with $0.18-0.75$ and tick resistance with $0.15-0.44$ showed high varaibilties, from very low to high heritabilities [21, 22, and 23]. Heritabilities for resistance to nematode were found to be $0.30-0.38$ and for trypanotolerance $0.30-0.88$ showing medium to high heritabilities $[22,24]$. Reports show $[1,22,25]$ Boran cattle to have adaptive traits to heat stress, external and internal parasites, and as well as some blood parasites such as trypanssomiasis and east cost fever.These adaptive mechanisms to the harsh environmental conditions, by Boran cattle is due to morphological, behavioural, physiological, neuro-endocrine, blood biochemical, metabolic, and molecular and cellular responses which are combined to promote survival and production in a specific environments [26].

\subsubsection{Morphological Adaptation}

Indigenous cattle breeds adapted to arid and semi-arid regions possess special morphological features, such as skin coat, which helps to provide better protection from direct solar radiation [27]. Phenotypically, the typical Boran cattle breed (Qorti subtype) have white color, large dewlap and well developed hump. But mostly they have light grey or fawn colour with black or dark brown shading on the neck, head, shoulders and hindquarters, shorter and more pendulous sheath, well developed udder, long legs, wide ears and large dewlap, small humps, a short tail and erect and short horns with dominantly thick base[20, 32]. Coat colour was one of the important morphological traits which impart adaptive ability to heat stressed livestock. Light or whitecoloured coated animals are recognized as being advantageous in hot tropical regions. Highly 
pigmented skin protects the deep tissues from direct short wave UV radiation by blocking its penetration. In addition, skin hair coat length, thickness and hair density also affect the adaptive nature of animals in tropical regions, where short hair, thin skin and fewer hair follicles per unit area are directly linked to higher adaptability to hot conditions[29, 30].Indigenous cattle breeds are more adapted to high temperatures, high solar radiation and dry conditions than exotic cattle breeds due to their high skin pore density which allows them to successfully regulate their body temperature [31].

Phenotypic characteristics are resultant of adaptation mechanisms of the breed. For instance, white/ light grey coloured coats are helpful in thermo-regulation ability in tropical regions as it reflects $50 \%$ to $60 \%$ of direct solar radiation compared with the dark-coloured animals $[1,28]$; long legs to trek long distance (usually more than $60 \mathrm{~km} /$ day) in search of feed and water [20, 25] and wide ear and large dewlap to increase surface area for metabolic heat dissipation [7, 33].

In addition, the Boran cattle have higher level of resistance to biting insects and tick infestation due to: (1) A highly sensitive and motile skin of Borana cattle with thick, well-developed layer of subcutaneous tissue causes the muscles beneath their skin to contract and move in reaction to insects landing on and biting them. This enables them to vigorously shake off external pests, (2) A very short hair coat makes it difficult for insects to attach onto hides of Boran cattle (3) A waxy and oily secretion from the skins of the Boran cattle makes them less desirable host for ticks and flies and (4) A long tail with a big well-formed twitch used to ride off vector flies for eye infection from Boran cattle [29, 34]. It was also reported that Boran cattle have prominent, protective eyebrows and long eyelashes which protect their eyes from bright sunlight, dust and other irritants factors that predispose cattle to pinkeye infection [1]. The Boran cattle (Kenyan Boran) tend to present some resistance to trypanosomal infection in the tsetse-infested regions of the east coast of North East Kenya [2]. Borana cattle both bulls and cows usually have horns and their horns are relatively smaller in size which was believed to have lower energy requirement for maintenance and have probably more adaptive capacity as compared to cattle breeds with large horns[1].

Morphological traits in livestock are highly important from the adaptation point of view, as they directly influence the heat exchange mechanisms between the animal and the surrounding environment [28]. 


\subsubsection{Behavioural adaptation}

280

281

282

283

284

285

286

287

288

289

290

291

292

293

294

295

296

297

298

299

300

301

302

303

304

305

306
In an effort to adapt to varying environmental conditions, the animals exhibit several behavioural responses. The most important behavioural responses studied in tropical cattle include: shade seeking, standing time, feed intake, defecating and urinating frequency, water intake and frequency [35]. Tropical indigenous cattle breeds were observed to be highly adapted to direct heat stress, spending more time for grazing than resting in shade. Zebu cattle have the ability to adapt their grazing behaviour in response to restricted grazing time or when no grazing is allowed during nights [36, 37, 38, 39]. Several studies show that different Zebu breeds spend more than $4 \%$ of their pasture time resting which varies between $4.4 \%$ and $10.12 \%$ [37, 38]. In a study involving Boran cattle, the resting time is as low as $2 \%$ [36]. The high grazing frequency and low resting time of the Boran show its special ability to utilize the available pasture efficiently during grazing time [39].

Another behavioural response to climate stress in ruminants is the reduction in feed intake and utilization in arid regions as adaptive response to regulate internal metabolic heat production under hot environment $[40,41]$ and decreasing water excretion by concentrating urine were also alternative strategies to adapt to severe climate stress for livestock in arid and semi-arid of East African rangelands $[41,42]$. Increased standing and decreased lying time was also reported to be associated with higher ambient temperatures [43, 44]. Generally, heat stressed animals tend to spend more time standing so that they can reorient themselves in different directions to avoid direct solar radiation and ground radiation. In addition, the standing position also obstructs the conductive heat transfer into the animal body due to the presence of a layer of air adjacent to the skin, and also facilitates the dissipation of body heat load to the surroundings by increasing the amount of skin exposed to air flow or wind.

Boran cattle breed have developed high degree of favourable behavioural adaptation to harsh environment due genetic basis, human and natural selection for long generations [2]. They have developed ability to withstand periodic shortage of water and feed, ability to walk long distances in search of water and feed and ability to digest low quality feeds from degraded arid rangelands [20]. The Boran cattle are non-selective aggressive grazers and browsers [1]. The Boran herd have 
a positive social behaviour with good mothering ability which may reduce chance of being attacked by predatorsadapted to free grazing rangelands [37].

\subsubsection{Physiological adaptations}

310 Some of the physiological mechanisms of adaptations to heat stress are respiration rate, rectal 311 temperature, pulse rate, skin temperature and sweating rate. Increased sweating rate, high 312 respiration rate, vasodilation with increased blood flow to skin surface, reduced metabolic rate, 313 decreased dry matter intake and altered water metabolism are the physiologic responses that have 314 negative impact on the production and reproduction of the cows [45]. All these physiologic 315 responses are substantial and prolonged in Bos taurus than in Bos indicus [46]. Hence the 316 317 the tropical cattle [26].

318 Excessive heat causes decreased food intake and disturbances in protein and energy metabolism, mineral balance, enzymatic reactions, hormones and metabolites secretion in the blood [26]. 320 Metabolic disorders caused by thermal stress lead to reduced milk production, growth and 321 reproductive rates and increase the susceptibility of animal diseases causing economic loss [48, 322 49, 50]. Moreover, climate change causes an increase in average temperature and reduced rainfall, 323 putting the sustainability of the livestock production system in risk, especially in countries such as 324 Ethiopia which already has high air temperature averages and grazing systems dependent on the rainy season $[6,7,51]$.

326 The Boran cattle is one of the most productive indigenous cattle breed in east Africa which is 327 capable of surviving and reproducing under the prevailing harsh climatic, nutritional and 328 management conditions of the region while maintaining good productivity on poor forage and low 329 water availability [1, 33]. This is because they have physiologically adapted and develop lower 330 maintenance requirements than Bos taurus cattle [52]. Boran cattle have higher level of lipoprotein-lipase enzyme activity in the subcutaneous fat depot, which enables them to survive

332 drought in the Borana rangelands with drastic recoveries after drought years when pasture 333 condition improves $[1,7,25]$. The Boran cattle are non-selective feeders and browsers which give them the ability utilizeshrubs, trees and dry unpalatable grasses that often not consumed by other 335 cattle breeds $[6,29]$. 


\subsubsection{Neuro-endocrine response}

337 Several studies of various livestock species clearly established higher plasma cortisol level in 338 ruminants during heat stressed conditions [54]. [26] reported that the plasma cortisol level was significantly lower in multiple stressors groups (heat, nutrition and walking) as compared with individual (heat stress/nutritional stress) or combined stresses (heat and nutrition stress). Aldosterone is another steroid hormone released from the cortex of the adrenal glands and is involved in the regulation of water and mineral balance in the body. It is a well-established fact that during heat stress conditions ruminants may undergo severe dehydration, which may result in the activation of renin-angiotensin-aldosterone pathway to restore the water and electrolyte balance [55]. Severe dehydration may lead to increased secretion of antidiuretic hormone (ADH) through activation of renin-angiotensin-aldosterone system. The ADH hormone regulates the blood osmolality by increasing the water absorption in the kidneys, which also assists the excretion of concentrated urine in animals suffering from heat stress [56]. Studies on the responses of neuroendocrine mechanisms in Boran cattle breed are scarce in Ethiopia and this requires further investigation.

\subsubsection{Blood biochemical response}

352 Blood biochemical constituents and enzymes are fundamental biomarker for climate stress 353 adaptation in tropical livestock. There are several biochemical and enzymes reported to involve in 354 adaptation of livestock to climate stress. One of these events is an increasing trend of total blood 355 haemoglobin $(\mathrm{Hb})$ with an increase in environmental temperature which could be due severe 356 dehydration $[57,58]$. Plasma haptoglobin is also one of the most commonly used acute phase 357 proteins to assess the health and inflammatory response of animals [59]. [60] reported a 358 significantly higher production of haptoglobin in the blood plasma of Holstein-Frisian dairy cows 359 exposed to high heat load. In several experiments, significantly increased levels of packed cell volume (PCV) were observed in various livestock species suffering from heat stress ([28]. On the

361 other hand, a decreased concentration of plasma protein [46, 61] and cholesterol [46] were recorded in livestock exposed to elevated ambient temperatures. Further, there are reports which also established an increased concentration of free fatty acid in livestock exposed to heat stress $364[58]$. 
Antioxidant enzymes such as superoxide dismutase (SOD) and glutathione peroxidase (GPx) are synthesized in the body and provide protection from reactive oxygen species generated during heat stress [62].These antioxidants scavenge both intracellular and extracellular super oxides and inhibit lipid peroxidation of plasma membrane during the challenges of heat stress [63].[58] reported a significantly higher level of plasma malondialdehyde, SOD and GPx activities in Surti buffaloes during hot humid periods and hot dry periods indicating an increased free radical production during periods of heat stress. In addition to this, plasma antioxidant levels in the hot dry period were significantly higher than in the hot humid period indicating more stressful condition may lead to the elevated synthesis of free radicals [58]. There are also reports establishing significantly higher total antioxidant status (TAS) values in a hot dry season in ruminant animals [58]. All these findings establish the significance of blood biochemical responses to be one of the primary means used by animals to cope with adverse environmental conditions.

\subsubsection{Metabolic responses}

Metabolic adaptation is another important means through which animals tackle challenges of heat stress, essentially by reducing the metabolic heat production [64]. Thyroid hormones play an important role in regulating the thermogenesis and are also identified as an indicator for assessing the thermo-tolerance of the farm animals [65]. Thyroid hormones, namely triiodothyronine $\left(\mathrm{T}_{3}\right)$ and thyroxine $\left(\mathrm{T}_{4}\right)$, play a vital role in metabolic adaptation and growth performance of animals [59]. During heat stress, serum and plasma concentrations of $\mathrm{T}_{3}$ and $\mathrm{T}_{4}$ reduce and are likely to be due to the direct effect of heat stress on the hypothalamo-pituitary and thyroid axis to decrease the production of thyrotropin-releasing hormone, which will limit basal metabolism [64]. Reduced concentrations of circulating $\mathrm{T}_{3}$ and $\mathrm{T}_{4}$, were an indicative of an attempt to reduce metabolic rate and thus metabolic heat production in heifers [66].

During periods of high ambient temperatures, some metabolic enzymes increase their activity, the levels of activity of these enzymes in plasma can be informative of how various organs are responding and adapting to heat load and such enzymes play a vital role in the diagnosis of welfare of animals [62]. Acid phosphatase (AP) and alkaline phosphatase (ALP) are two major enzymes associated with the metabolic activities in animals. The levels of these enzymes are generally low in heat stressed animals, which could be attributed to a metabolic shift in the animals 
[62].Likewise, [46] reported a decrease in ALP during summer in ruminants, which they attributed to the dysfunction of the liver during heat stress exposure. Aspartate aminotransferase (AST) and alanine aminotransferase are two important metabolic enzymes that increase during heat stress exposure in sheep [67] and goats [62]. These authors concluded that such increase in the activity of these enzymes is due to the higher adaptive capability of the animals to cope with heat stress [68].

Another important metabolic regulator is non-esterified fatty acids (NEFA) in plasma and serum [59]. Low NEFA concentrations are mostly reported in heat stressed dairy cows. It is thought that this is an attempt to increase glucose utilization which will result in lower metabolic heat production [69]. However, [70] reported an increase in NEFA production of dairy cows during summer compared with winter, which they attributed to an attempt by the animals to maintain energy balance. In summary, at least in livestock, haptoglobin, NEFA, thyroid hormones $\left(\mathrm{T}_{3}\right.$ and $\mathrm{T}_{4}$ ) and liver enzymesare considered to be reliable indicators of metabolic adaptation to high heat load [59].

\subsubsection{Cellular and molecular responses}

The cellular level of adaptation is one of the acute systemic responses to heat stress and it plays a significant role in imparting thermo-tolerance to animals. Gene networks within and across the cells respond to a higher temperature through both intra-and extracellular signals that result in cellular adaptation. Cattles evolved in hot climates had acquired different thermo-tolerant genes when exposed to a higher temperature [2]. Heat stress was found to alter several molecular functions such as DNA synthesis, replication and repair, cellular division and nuclear enzymes and DNA polymerases functions [71,72]. It also affects a complex array of cellular and molecular responses in livestock [73]. With the development of molecular biotechnologies, new opportunities are available to characterize gene expression and identify key cellular responses to heat stress [21]. For example, there are changes in the expression patterns of certain genes that are fundamental for thermo-tolerance at the cellular level in animals [62]. Such genes having a cellular adaptation function in animals are considered potential biomarkers for understanding stress adaptation mechanisms [26].The classical heat shock protein (HSP) genes, apoptotic genes and other cytokines and toll-like receptors are considered to be up regulated on exposure to heat stress. Several reports established the role of HSP70 during heat stress exposure in ruminant livestock 
424 and they identified this to be ideal molecular marker for quantifying heat stress response [41, 62].

425 Apart from this, several other genes such as Superoxidedismutase(SOD), nitric oxide synthase 426 (NOS), thyroid hormone receptor (THR) and prolactin receptor (PRLR) genes were found to be 427 associated with thermo-tolerance in ruminant livestock [26].

428 Furthermore, [41] a higher expression of HSP70 messenger RNA (mRNA) in the adrenal gland of 429 the multiple stressor groups, which could be attributed to the adaptive mechanism of livestockto 430 counter both the heat stress and nutritional stress. The significantly higher expression of adrenal $431 H S P 70$ in the multiple stressed animals as compared with animals subjected only to heat stress 432 could be attributed to additional nutritional stress in the multiple stresses group. The higher HSP70 433 expression in the adrenal gland could also be attributed to the hyperactivity of adrenal cortex to synthesize more cortisol as evident from this study [41\}. Similarly, the plasma HSP70 and expression pattern of peripheral blood mononuclear cell HSP70 also showed similar trends of significantly higher value in multiple stressor group animals as compared with control and individual (heat/nutritional) stress groups [41]. Studies have also indicated that HSP70s and their associated cochaperones participate in numerous processes essential to cell survival under stressful conditions. They assist in protein folding and translocation across membranes, assembly and disassembly of protein complexes, presentation of substrates for degradation and suppression of protein aggregation [73].

\subsubsection{Effects of climate change on Boran cattle production}

443

444

445

446

447

448

449

450

451

452
In Arid and semi-arid tropics, climate change has direct negative effect on adaptive capacity [74], growth [69], milk production [75], reproductive [76] and meat production [77] performances of livestock. Further, it can indirectly reduce livestock production by increasing annual variations of the quantity and quality of feed and water resources, reduced dry matter intake and feed utilization, increased thermal stress and sudden disease outbreaks $[2,78]$.The adverse impacts of heat stress on these productive functions depend on species and breed differences of livestock and the magnitude of this impact determines the adaptive potential of the animals.

Ethiopian Boran cattle are one of those cattle breeds reported for their special production, reproduction and adaptation traits under such scenario [5], particularly the Borana rangelands of Southern Ethiopia [19,74]. On other hand, Boran cattle breed is currently challenged by the 
453 adverse effects of climate change and other management factors. These are high rate genetic 454 dilution by other small sized zebu cattle through increasing pressure of breed admixture, 455 uncontrolled breeding program and the preference of small sized cattle breed with reduced 456 metabolic requirements as compared large size Borana cattle due to negative effect of climate 457 change on rangeland productivity $[6,74]$. There is also conversion of grazing lands to crop lands, 458 bush encroachment and lack of indigenous rangeland management practices [47, 48] hampered 459 rangeland productivity in the region. Lack of organized breed improvement programs and 460 improper selection of gene pool are also critical challenges of Boran cattle breed[7]. However, rate 461 of genetic dilution of Boran cattle by other zebu cattle and the specific reasons why Borana 462 pastoralists decided to admixtheir pure Boran cattle with local small sized short horn zebu cattle 463 require further investigation.

464

465

466

467 for Boran cattle breed are shown in Table 2.

468 Table 2. Mean phenotypic traits of production and reproduction in Boran cattle breed

\begin{tabular}{|c|c|c|c|c|c|c|c|}
\hline Traits & $\mathbf{A b b}$ & Unit & Articles & Records & Mean & s. d. & $\mathrm{CV}(\%)$ \\
\hline \multicolumn{8}{|c|}{ Reproduction traits } \\
\hline Calving interval & $\mathrm{CI}$ & Days & 16 & 7395 & 421.17 & 126.72 & 30.1 \\
\hline Days open & $\mathrm{DO}$ & Days & 14 & 7387 & 162.16 & 35.06 & 21.6 \\
\hline $\begin{array}{l}\text { Age at first } \\
\text { service }\end{array}$ & AFS & Months & 13 & 3891 & 34.27 & 6.45 & 18.8 \\
\hline $\begin{array}{l}\text { Age at first } \\
\text { calving }\end{array}$ & $\mathrm{AFC}$ & Months & 13 & 3638 & 44.23 & 6.47 & 14.6 \\
\hline $\begin{array}{l}\text { Number of } \\
\text { service per } \\
\text { conception }\end{array}$ & $\mathrm{NSC}$ & Number & 17 & 9529 & 1.71 & 0.29 & 17.0 \\
\hline \multicolumn{8}{|c|}{ Growth and carcass traits } \\
\hline Birth weight & BWT & $\mathrm{Kg}$ & 12 & 1762 & 25.43 & 3.49 & 13.7 \\
\hline
\end{tabular}




\begin{tabular}{|c|c|c|c|c|c|c|c|}
\hline Weaning weight & WWT & $\mathrm{Kg}$ & 10 & 1608 & 116.63 & 57.86 & 49.6 \\
\hline $\begin{array}{l}\text { Six month } \\
\text { weight }\end{array}$ & SMWT & $\mathrm{Kg}$ & 5 & 296 & 95.5 & 23.33 & 24.4 \\
\hline Yearling weight & YWT & $\mathrm{Kg}$ & 8 & 1298 & 209.27 & 52.02 & 24.9 \\
\hline $\begin{array}{l}18 \text { months } \\
\text { weight }\end{array}$ & EMWT & $\mathrm{Kg}$ & 6 & 491 & 212.63 & 56.01 & 26.3 \\
\hline Adult weight & AWT & $\mathrm{Kg}$ & 8 & 463 & 356.85 & 91.51 & 25.6 \\
\hline $\begin{array}{l}\text { Average daily } \\
\text { gain }\end{array}$ & ADG1 & $\mathrm{G}$ & & & & & \\
\hline $\begin{array}{l}\text { from birth to } \\
\text { weaning }\end{array}$ & & & 10 & 865 & 402.37 & 120.26 & 29.9 \\
\hline $\begin{array}{l}\text { Average daily } \\
\text { gain }\end{array}$ & ADG2 & $\mathrm{G}$ & & & & & \\
\hline $\begin{array}{l}\text { from weaning to } \\
\text { adult age }\end{array}$ & & & 7 & 802 & 243.66 & 84.93 & 34.9 \\
\hline \multicolumn{8}{|c|}{ Milk yield and composition traits } \\
\hline Lactation yield & LYD & $\mathrm{Kg}$ & 10 & 3256 & 596.3 & 165.12 & 27.7 \\
\hline 305 days yield & $305 Y D$ & $\mathrm{Kg}$ & 7 & 2751 & 506 & 91.72 & 18.1 \\
\hline Lactation length & $\mathrm{LL}$ & Days & 9 & 2901 & 230.76 & 40.66 & 17.6 \\
\hline Daily milk yield & DYD & $\mathrm{Kg}$ & 10 & 3627 & 2.02 & 0.48 & 23.9 \\
\hline $\begin{array}{l}\text { Total lactation } \\
\text { yield }\end{array}$ & TLYD & $\mathrm{Kg}$ & 8 & 2226 & 2440.51 & 672.36 & 27.6 \\
\hline Milk fat & $\mathrm{MF}$ & $\%$ & 7 & 4255 & 5.01 & 1.23 & 24.7 \\
\hline Milk protein & MP & $\%$ & 7 & 1751 & 3.63 & 0.37 & 10.1 \\
\hline Lactose content & ML & $\%$ & 7 & 459 & 4.65 & 0.60 & 12.9 \\
\hline Solid not-fat & SNF & $\%$ & 7 & 1714 & 8.93 & 0.27 & 3.02 \\
\hline Total solid & $\mathrm{TS}$ & $\%$ & 7 & 2531 & 14.78 & 1.07 & 7.3 \\
\hline
\end{tabular}




\begin{tabular}{|c|c|c|c|c|c|c|c|}
\hline Short chain FA & TSFA & $\%$ & 5 & 125 & 64.5 & 4.33 & 6.7 \\
\hline Medium chain & TMCFA & $\%$ & & & & & \\
\hline FA & & & 5 & 125 & 33.2 & 3.81 & 11.5 \\
\hline Polyunsaturated & TPUFA & $\%$ & & & & & \\
\hline FA & & & 5 & 125 & 2.79 & 0.6 & 21.5 \\
\hline Omega-3 FA & $\mathrm{W}-3 \mathrm{FA}$ & $\%$ & 5 & 125 & 0.38 & 0.14 & 36.8 \\
\hline Omega-6 FA & W-6FA & $\%$ & 5 & 125 & 2.41 & 0.47 & 19.5 \\
\hline
\end{tabular}

The number of published articles reported were higher for CI, NSC, DO, AFS, AFC, BW, WW, ADG2, LYD and DMY (Table 2) traits, suggesting their importance for the Boran cattle breeding 472 program. The number of studies as well as the records per articles were comparatively lower for 473 some growth and milk production traits than reproductive traits as these traits are mainly age and 474 sex-specific and difficult to measure periodically. The lowest coefficients of variations were 475 estimated for milk composition traits indicating that the number of studies and records on the 476 specific breed is limited and requires more investigation. In addition, the phenotypic variations for 477 these specific traits are biologically limited [79]. On the other hand, the higher coefficient of 478 variations was observed for WWT (49.6\%), Omega-FA (36.8\%), ADG (34.9\%) and CI (30.1\%), 479 showing that there is larger phenotypic variation in these traits than in others (Table 2).

\subsubsection{Quality control}

482 The possibility and consequences of bias should be considered in all systematic and meta-reviews. 483 For reproduction and production traits considered in this review, weighted box plots were 484 constructed by using RSEi values of each trait to identify potential outlier and to insure the 485 reliability of the data for the meta-analysis as this method was recommended as effective tool to 486 evaluate reviews with a smaller number of articles and higher CV in published parameters [80]. 487 Based on suggestion of [14], none of the traits recorded revealed to have RSEi higher than $25 \%$ 488 (Figure 2) and thus, the available data on the important traits were considered.

489 The wide variability among estimates generated by the different studies for each trait observed by 490 the higher coefficient of variation (CV) values in the traits considered in the reviews showed that 
491 there are large variation in the traits both between studies and within studies thus, random effect

492 model is the methods of choice for the meta-analysis of the traits [12]. In addition, meta-analysis

493 based on random-effect model is relevant for inferences at the population level [79, 81, 82].

494 For heritability estimates of reproduction and production traits, only direct heritability was 495 considered excluding of maternal heritability and additive effect of environment due to limited 496 data records on the considered parameters. Due to small numbers of articles reporting the 497 reproduction and production heritability estimates and high variation among them, we were unable 498 to investigate possible correlations in the present review; this analysis might be possible in the 499 future when more studies become available on the Boran cattle breed.

500

501

502

503

504 505

506

507

\subsubsection{Reproduction and production performances of Boran cattle and other cattle breeds}

\subsubsection{Reproductive characteristics}

Comparisons of the reproductive performance of Ethiopian Boran with other indigenous cattle breeds indicated that Boran cattle have better reproductive performance (Table 3). The breed have shorter female age at first matting (FAFM), age at first calving_(AFC), calving interval(CI), days open (DO) while longer reproductive life time for male (RLTM) and reproductive life time for female (RLTF) as well as comparable male age of fertility for mating(MAFM). These traits vary from low to high in heritability and are more challenging to record [87].

Table 3: Average reproduction and production performances of Boran cattle as compared to other Ethiopian cattle breeds

\begin{tabular}{llllllll}
\hline \multicolumn{7}{c}{ Reproductive performances(months) } \\
\hline Breed & MAFM & FAFM & AFC & CI & RLTM(yr) & RLTF(yr) & $\begin{array}{l}\text { DO } \\
\text { (day) }\end{array}$ \\
\hline Borana & 47.4 & 37.6 & 48.6 & 15.3 & 9.6 & 11.2 & 240 \\
Horro & 46.9 & 54.8 & 50.0 & 17.0 & 7.2 & 13.6 & 272 \\
Begait & 42.3 & 39.3 & 53.1 & 18.2 & 6.8 & 9.6 & 329 \\
Arsi & 36.3 & 41.8 & 49.1 & 14.5 & 7.4 & 12.1 & 152 \\
Fogera & 45.4 & 42.2 & 55.1 & 21.2 & 6.8 & 11.3 & 285 \\
Sheko & - & - & 42.2 & 16.5 & 6.5 & 14.7 & 248 \\
\hline \multicolumn{7}{c}{ Production performances } \\
\hline
\end{tabular}




\begin{tabular}{llllll}
\hline Breed & DMY(kg/d) & LMY(kg) & LL(months) & BW(kg) & MW (kg) \\
\hline Borana & 3.2 & 596.3 & 8.7 & 23.1 & 394.2 \\
Horro & 1.65 & 512.9 & 8.64 & 19.9 & 250 \\
Begait & 2.44 & 539.1 & 6.00 & 22.6 & 294 \\
Arsi & 1.82 & 809 & 9.3 & 17.3 & 264 \\
Fogera & 2.93 & 777 & 16.9 & 21.9 & 384 \\
Sheko & 2.79 & 774 & 10.1 & 16.1 & 275
\end{tabular}

\section{Source: $[5,75,83,84,85,86]$}

In Ethiopia, breeding mainly relies on natural service and, therefore, acceptable bull fertility is also critical [5]. Factors that determine a bull's fertility and performance include plane of nutrition [5], structural soundness, capability of the reproductive organs, quality of the semen, libido level and servicing capacity [88]. Under pastoralist management conditions, age at first calving of Borana cattle is about four years of age [89]. At Abernossa ranch in Ethiopia, weight and age at puberty in heifers were found to be about $155 \mathrm{~kg}$ and 22 months, respectively. Calving rate under a singlesire mating system was also improved to above $80 \%$ [5], compared to about $45 \%$ under pastoral management conditions [89]. These results would therefore indicate the improvement that could be achieved through proper selection scheme and better management. On the other hand, Ethiopian Boran had longer calving interval, lower breeding efficiency, delayed age at first service and age at first calving and longer days' open compared with their Friesian crosses. These differences in reproduction performance between Ethiopian Boran and the crosses are comparable with those obtained for local cattle and their crosses in Ethiopia [83, 90]. Thus, the more advanced age at first calving obtained in the Boran compared with their exotic crosses indicated the potential that could be exploited by merely improving management. However, there was no significant difference in number of services per conception among the genetic groups [5].This could due the fact that nutrition [83] and inseminator effects [25] are more important contributors to the variation in number of services per conception than genotype. 


\subsubsection{Growth and carcass characteristics}

532 Table 3 indicates comparative summary of birth weight (BW) and mature weight (MW) of six

533 Ethiopian cattle breeds. Boran cattle had better performance in both growth traits (Table 3).

534 Additionally, performance of Boran has been substantially improved through improvement in 535 management and selection under intensive system. For example, the improved Boran had birth 536 weight of 30kg in Kenya [4] and weaning weight of $158 \mathrm{~kg}$ at Abernossa ranch in Ethiopia [83]. 537 This variation indicates the potential that can be exploited by within breed selection and 538 improvement in management. Growth performance of Boran and their crosses as beef animal has

539 been evaluated in different parts of the world. For example, the value of the Boran for beef 540 production in the tropics is clearly shown in crossbreeding studies in Kenya 541 (www.borankenya.org). In this experiment the F1 Angus/Boran steer weighed $426 \mathrm{~kg}$ when sold 542 at 13 months with a daily gain of $1.36 \mathrm{~kg}$. In Australia (www.boransaustralia.com), it is generally 543 believed that using Boran bulls for crossbreeding is the quickest way of improving the commercial 544 potential of beef herds, because one of the most important attributes of the Boran is its ability to 545 transmit hybrid vigour to the traditional beef breeds of Australia (including Brahman and its'

546 crosses). The higher growth performance observed for the crossbred calves in comparison with the

547 Ethiopian Boran cattle could be due to the effects of breed and heterosis on the growth performance 548 of crossbred cattle [5]. The average adult live weight differs depending on the status of 549 improvement, level of management and production system. For example, mature bulls of the 550 Improved Boran in Kenya were reported to weigh 550-850 kg and those for cows were 400-550 $551 \mathrm{~kg}$ [4]. The birth weight under range condition of Ethiopia is indicated to be $18 \mathrm{~kg}$, while it is 552 nearly $25 \mathrm{~kg}$ in research stations of Ethiopia and in the commercial ranches of Kenya [2]. Due to 553 this good beef performance, it is indicated that Boran could be used to improve small East African 554 Zebu [5].

555 The Boran had higher carcass weight when compared with Angoni and Barotse breeds of the same 556 age group, while Boran and Angoni were comparable with regard to dressing percentage [74]. 557 Carcass characteristics differ between breeds and are influenced by the plane of nutrition and 558 production system [86]. Selection for these traits is greatly influenced by the market demand. In 559 the Ethiopian context, export markets demand lean meat whereas when the target is local market, 
fattened cattle are required [5, 86]. Therefore, the breeding, feeding and other management conditions should be designed in such a way that the requirements of the specific market are met.

It is established that Boran produces high quality beef by utilizing low quality forage. This is substantiated by data from the FAO/UNDP feedlot trial at Lanet in Kenya, where 7625 Boran and crossbreds were fed between 1968-73 (www.borankenya.org). Similarly, the performance of improved Boran as a beef breed was reported higher in South Africa, USA and Australia [4]. In addition, Boran cattle are less affected by mild drought shocks and have fast recovery rate [20]. In Ethiopia, literature report on beef attributes of Ethiopian Boran is scanty. Some of the literatures on growth performance of Ethiopian Boran cattle presented in Table 3 are based on data from crossbreeding studies where Ethiopian Boran was used for dairy production. There is therefore, a need to investigate the beef qualities of the Ethiopian Boran for future uses.

\subsubsection{Milk yield and quality characteristics}

Milk production performance of Ethiopian Boran compares fairly well with other indigenous Ethiopian breeds (Table 3). Boran cattle had better daily milk yield (DMY), lactation milk yield (LMY) and comparable lactation length(LL) among Ethiopian cattle breed under grazing systems. However, the improved Boran in Kenya had much higher performance than the unimproved Ethiopian Boran. In Kenya, improved Boran cows could produce $1130 \mathrm{~kg}$ milk over a 36 week period during with calves suckled three times a day producing butter fat percentage of 5.7, 5.8, 5.9 and 6.1, respectively [4]. But under more favourable production environment, Boran cows produced up to $1657 \mathrm{~kg}$ of milk per 252-day lactation [2]. On the other hand converting calf growth up to 7 month in to milk intake and adding recorded values of milk off-take for human consumption; lactation milk yield of Boran cows was calculated to be $843 \mathrm{~kg}$ under the pastoralist system in Ethiopia [90]. Moreover, crossbreeding of Ethiopian Boran with Holstein Friesian resulted in improved milk production [5]. For example, 50\% Holstein Friesian crosses had a fourfold increase over the Ethiopian Boran breed in terms of lactation milk yield,305-days milk yield, daily milk yield and life time milk yield; they were also milked for 97 more days than Ethiopian Boran.

In general, meta-analysis for performances of Boran cattle compared with other Zebu cattle breeds as beef and/or dairy cattle are described by four categories of traits namely, reproduction, growth, milk production, and carcass yield and quality traits (Table 2). Although their production potential 
590 is less compared with exotic and cross breeds, the level of production of Boran cattle is relatively 591 stable during harsh conditions where high producing animals are at risk [1]. Furthermore, during 592 periods of extreme heat stress, water scarcity and reduced pasture availability, they maintain their 593 reproductive potential due to their smaller body size whereas the larger exotic animals may face 594 reproductive impairments which could be attributed to their higher maintenance energy 595 requirements $[5,20]$.

\section{$596 \quad$ 3.3.3.4. Heritability of production and reproduction traits in Boran cattle}

597 Direct and maternal-heritability estimates of reproductive and production traits with respective $59895 \%$ confidence intervals and the $\mathrm{I}^{2}$ index to test the significance of heterogeneity among studies, 599 for each trait, for Boran cattle are shown in Table 4. Direct heritability estimates for reproduction 600 traits ranged from lower to medium magnitude. Lower heritability estimateswere observed for DO 601 (0.040) and CR (0.042), for whichthe impudence of environmental factors is more evident. 602 Medium heritability were estimated for longevity (0.08), SPC (0.081), CI (0.03) and AFC (0.215), 603 indicating relatively better response to selection for these traits as compared to the other indicated 604 reproductive traits. Usually, indigenous cattle in Ethiopia are raised on extensive production 605 systems, which are often characterized by high temperatures and periods of feed and water scarcity that might affect the reproductive performances of animals [5].

Table 4: Number of articles to estimate direct and maternal heritability $\left(\mathrm{N}_{\mathrm{d}}\right.$ and $\mathrm{N}_{\text {mat }}$ respectively), direct and maternal heritability ( $h^{2}$ and $h^{2}$ mat respectively) estimated from meta-analysis using random-effects model, $95 \%$ confidence interval for heritability (95\% CI and 95\% CI mat respectively) and the $\mathrm{I}^{2}$ index to test heterogeneity in each traits( $\mathrm{I}^{2}$ and $\mathrm{I}^{2}$ mat respectively)

\begin{tabular}{|c|c|c|c|c|c|c|c|c|c|c|c|}
\hline \multirow[t]{2}{*}{ Trait } & \multirow[t]{2}{*}{$\mathbf{N}_{\mathbf{d}}$} & \multirow[t]{2}{*}{$\mathbf{h}^{2}$} & \multicolumn{2}{|c|}{$95 \% \mathrm{CI}$} & \multirow[t]{2}{*}{$\begin{array}{l}\mathbf{I}^{2} \\
(\%)\end{array}$} & $\begin{array}{l}\text { Repeatability } \\
(\%)\end{array}$ & \multirow[t]{2}{*}{$\begin{array}{l}\mathbf{N} \\
\text { mat }\end{array}$} & \multirow[t]{2}{*}{$\mathbf{h}^{2}$ mat } & \multicolumn{2}{|c|}{$95 \%$ CI mat } & \multirow[t]{2}{*}{$\begin{array}{l}\mathbf{I}^{2} \\
\text { mat } \\
(\%)\end{array}$} \\
\hline & & & LLQ & ULQ & & & & & LLQ & ULQ & \\
\hline \multicolumn{12}{|c|}{ Reproduction traits } \\
\hline $\mathrm{AFC}$ & 6 & 0.22 & 0.20 & 0.23 & 99.1 & 51.2 & & & & & \\
\hline $\mathrm{CI}$ & 5 & 0.08 & 0.01 & 0.16 & 92.8 & 62.5 & & & & & \\
\hline SPC & 7 & 0.08 & 0.04 & 0.12 & 87.1 & 54.7 & & & & & \\
\hline DO & 6 & 0.04 & 0.03 & 0.05 & 72.4 & 48.2 & & & & & \\
\hline $\mathrm{CR}$ & 8 & 0.04 & 0.02 & 0.06 & 91.3 & 71.7 & & & & & \\
\hline Longevity & 4 & 0.08 & 0.05 & 0.11 & 83.2 & 88.5 & & & & & \\
\hline
\end{tabular}




\begin{tabular}{lccccccccccc} 
ADG & 7 & 0.46 & 0.34 & 0.58 & 72.1 & & 4 & 0.2 & 0.06 & 0.34 & 69.6 \\
BWT & 9 & 0.25 & 0.14 & 0.36 & 80.7 & & 6 & 0.09 & 0.04 & 0.15 & 82.1 \\
WW & 6 & 0.24 & 0.13 & 0.35 & 92.1 & & 4 & 0.14 & 0.07 & 0.21 & 90.1 \\
YW & 8 & 0.27 & 0.07 & 0.46 & 87.2 & & 7 & 0.20 & 0.13 & 0.26 & 92.4 \\
Milk yield traits & & & & & & & & & & \\
DMY & 8 & 0.13 & 0.09 & 0.17 & 67.4 & 32.7 & 5 & 0.34 & 0.15 & 0.53 & 56.9 \\
LYD & 7 & 0.19 & 0.13 & 0.26 & 45.2 & 38 & 6 & 0.06 & 0.03 & 0.10 & 49.2 \\
LL & 5 & 0.12 & 0.07 & 0.16 & 67.4 & 37.7 & 4 & 0.2 & 0.14 & 0.26 & 68.3 \\
LYD & 6 & 0.20 & 0.05 & 0.07 & 50.4 & 26 & & & & & \\
305YD & 5 & 0.18 & 0.04 & 0.07 & 55.2 & 23 & & & & & \\
LL & 4 & 0.26 & 0.10 & 0.30 & 60.7 & 46 & & & & & \\
Milk composition & traits & & & & & & & & & \\
Fat\% & 3 & 0.49 & 0.43 & 0.55 & 91.2 & 0.98 & & & & & \\
protein\% & 3 & 0.26 & 0.32 & 0.34 & 62.1 & 0.59 & & & & & \\
SNF\% & 3 & 0.46 & 0.44 & 0.50 & 72.4 & 0.93 & & & & & \\
TS\% & 3 & 0.45 & 0.52 & 0.57 & 91.2 & 0.99 & & & & & \\
\hline
\end{tabular}

609 These phenomena is quite severe for poorly adapted exotic and crossbreds [91], but for Boran 610 cattle breed which had better adaption to tropical environment, the observed heritability estimates 611 were from lower to medium (Table 4), implicating selection response for AFC should be faster 612 than other traits for Boran cattle. Similar trend was observed for reproduction traits of Nellore 613 cattle in Brazil [79].

614 Direct heritability estimates for the growth traits ranged from medium in BWT $(0.25), \mathrm{WW}(0.243)$, 615 and $\mathrm{YW}(0.265)$ to higher in $\mathrm{ADG}(0.46)$ showing that relatively higher response to selection for 616 ADG trait than other growth traits in Boran cattle breed (Table 4). It shows that ADG, birth 617 weight and mature weight have the highest heritability among the production traits which had good 618 correlation with FCR explaining that accelerated genetic progress could be obtained for these 619 traits through selections in Boran cattle [19]. Similarly, direct heritability estimates for milk 620 production and composition traits ranged from medium to higher magnitude, indicating better 621 response for selection for milk composition traits compared to milk yield traits in Boran cattle. 622 The heritability estimates for growth for Nellore cattle [79] and other Zebu cattle breeds[93] 623 corroborates the current study for Boran cattle. 
Table 5: Summary of ranges of heritability values for reproduction and production traits of Tropical cattle

\begin{tabular}{lll}
\hline Reproductive traits & $\mathbf{h}^{2}$ & References \\
\hline Age at first calving & $0.04-0.31$ & {$[91,92]$} \\
Calving date & $0.02-0.09$ & {$[92]$} \\
Calving success & $0.03-0.27$ & {$[92]$} \\
Calving rate & 0.04 & {$[91]$} \\
Calving interval & $0.02-0.13$ & {$[91,92]$} \\
Days open & 0.04 & {$[83]$} \\
Longevity & 0.08 & {$[100]$} \\
Production traits & & {$[94,95]$} \\
Birth weight (direct) & $0.21-0.4$ & {$[94,95]$} \\
Birth weight(maternal) & $0.05-0.14$ & {$[94,96]$} \\
Weaning weight(direct) & $0.12-0.29$ & {$[94,96]$} \\
Weaning weight(maternal) & $0.11-0.21$ & {$[94,95]$} \\
Yearling weight & $0.13-0.26$ & {$[92,94]$} \\
Final weight & $0.13-0.42$ & {$[95,97]$} \\
Mature weight & $0.24-0.41$ & {$[98]$} \\
Average daily gain (ADG) & 0.38 & {$[99]$} \\
Feed conversion ratio (FCR) & $0.23-0.41$ & \\
\hline
\end{tabular}

624 Heterogeneity among studies were moderate in milk yield traits by $\mathrm{I}^{2}$ index (50 to $75 \%$ ) and higher 625 in reproduction, growth and milk composition traits with $\mathrm{I}^{2}$ index (>75\%). These results reinforced 626 the importance of accounting this heterogeneity in selecting random effect model in the meta627 analysis reviews of the studies (Table 4).

628 The weight and milk production performances of Boran calves are also affected by the maternal 629 genetic effect from dam. In general, maternal-heritability estimates for growth traits had a low to 630 medium magnitude (ranging from 0.089 to 0.20 ), indicating that the genetic progress for these 631 maternal effects is slow in this breed. Similar trend was observed for milk production traits. It is 632 well known that the initial phases of growth traits are influenced by the maternal effect and 633 ignoring these effects may lead to bias in many situations [94].In general, higher heritability 
634 estimates were reported in the studies for milk composition traits followed by growth traits and

635 milk yield traits but lower heritability estimates were reported for reproduction traits in Boran 636 cattle except trait for AFC. Since meta-analysis brings together published parameter estimates 637 provided by studies based on populations at different stages of selection, with different sample 638 sizes and considering distinct effects in the model, it is expected that the true parameter may vary 639 from study to study. In meta-analysis, the estimated confidence intervals of the studied traits were 640 narrower than those obtained from individual published articles. In Boran cattle, data on 641 heritability estimates for carcass traits were limited for this meta-analysis which requires more 642 studies in the future.

643 On the other hand, heritability for average daily gain and feed conversion ratio were estimated to 644 be medium for other African cattle breeds (Table 5). The summary of ranges of heritability for 645 tropical cattle breeds indicate that they have lower heritability for reproductive traits except for $646 \mathrm{AFC}$ and lower to medium values for production traits. Similar trends were observed in the current 647 meta-analysis for both reproduction and production traits of Boran cattle.

\subsubsection{Genetic correlations between reproduction and production traits in Boran cattle}

649 Genetic-correlation estimates with the respective $95 \%$ confidence interval and the $\mathrm{I}^{2}$ index to 650 quantify the degree of heterogeneity among the studies were shown in Table 6 for each trait pairs.

\begin{tabular}{|c|c|c|c|c|c|}
\hline \multirow[t]{2}{*}{ Traits } & \multirow[t]{2}{*}{$\mathbf{N}_{\mathbf{d}}$} & \multirow[t]{2}{*}{$\mathbf{r g}_{\mathrm{g}}$} & \multicolumn{2}{|c|}{$95 \% \mathrm{CI}$} & \multirow[t]{2}{*}{$\mathbf{I}^{2}(\%)$} \\
\hline & & & LLQ & ULQ & \\
\hline AFCXCD & 4 & 0.090 & 0.086 & 0.094 & 88.4 \\
\hline AFCXCI & 4 & -0.030 & -0.035 & -0.024 & 97.1 \\
\hline CDXCI & 5 & 0.010 & 0.008 & 0.012 & 84.9 \\
\hline DOXPR & 4 & -0.99 & -0.991 & -0.988 & 95.3 \\
\hline BWXWW & 4 & 0.560 & 0.285 & 0.834 & 88.3 \\
\hline BWXYW & 3 & 0.305 & 0.156 & 0.456 & 91.6 \\
\hline BWXMW & 5 & 0.587 & 0.373 & 0.801 & 89.2 \\
\hline WWXYW & 4 & 0.600 & 0.426 & 0.774 & 82.5 \\
\hline WWXMW & 5 & 0.894 & 0.733 & 1.056 & 99.9 \\
\hline LLXLYD & 4 & 0.885 & 0.679 & 1.09 & 99.7 \\
\hline
\end{tabular}




\begin{tabular}{llllll} 
305YDXLL & 5 & 0.410 & 0.155 & 0.665 & 87.5 \\
305YDXLYD & 3 & 0.340 & 0.242 & 0.438 & 83.8 \\
305YDXDMY & 3 & 0.297 & 0.120 & 0.474 & 99.9 \\
LYDXDMY & 3 & 0.524 & 0.329 & 0.720 & 93.7 \\
FXP & 2 & 0.510 & 0.275 & 0.745 & 99.7 \\
FXSNF & 2 & 0.160 & 0.062 & 0.258 & 82.7 \\
FXTS & 2 & 0.920 & 0.626 & 1.214 & 86.4 \\
PXSNF & 2 & 0.710 & 0.612 & 0.808 & 93.1 \\
PXTS & 2 & 0.820 & 0.644 & 0.996 & 99.1 \\
SNFXTS & 2 & 0.780 & 0.662 & 0.898 & 92.7 \\
\hline
\end{tabular}

Except correlation involving AFCXCI, CDXCI and DOXPR which assumed negative values, all other correlation estimates were positive. Higher correlation estimates were observed between WWXYW, WWXMW, PXSN, PXTS, LLXYD and SNFXTS trait pairs, while medium correlation estimates for WXWW, BWXMW, and FXP and lower correlation estimates for 305YDXLL,305YDXLD,305YDXDMY,LYDXDMY, FXSNF and BWXYW for Boran cattle breed. Similar to heritability estimates, the estimated confidence interval of genetic correlations was narrower than reported in individual published studies. All correlation estimates presented higher heterogeneity among studies by the $\mathrm{I}^{2}$ index $\left(\mathrm{I}^{2}>75 \%\right)$ which justify the use of randomeffects model. In general, a small number of articles reporting genetic correlation estimates were found for purebred Boran cattle. This highlighted the requirement for studies investigating these estimates, which, in general, also presented high standard errors in relation to heritability estimates (Table 6). Estimated genetic correlations among some reproduction and production traits in these studies are in line with summary of genetic correlations of fertility and production traits for tropical zebu cattle in East Africa (Table 7). Except for correlation between AFC and CD, the other correlation coefficient between pairs of reproduction traits were negative explaining improvement

Table 7: Genetic correlations (rg) for specific fertility and production traits in tropical cattle breeds

Traits $\mathbf{h}^{2} \quad$ References

\section{Reproductive traits}

$\begin{array}{lll}\text { Age at first calving and calving date } & 0.09- & {[92,100]} \\ & 0.88 & \\ & -0.03- & {[92,100]} \\ \text { Age at first calving and calving } & 0.44 & \\ \text { interval } & & \\ \text { Calving date and calving interval } & 0.01- & {[92,100]} \\ & 0.75 & \end{array}$




$\begin{array}{lll}\text { Calving success and calving date } & -0.95 & {[100]} \\ \text { Days to calve and pregnancy rate } & -0.99 & {[92]} \\ \text { Production traits } & & \\ \text { Birth and weaning weight } & 0.45- & {[92,95]} \\ \text { Birth and yearling weight } & 0.78 & \\ & 0.28- & {[95,101]} \\ \text { Birth and final weight } & 0.57 & \\ \text { Birth and mature weight } & 0.45-0.6 & {[95,102]} \\ \text { Weaning and yearling weight } & 0.86 & {[95]} \\ \text { Weaning and final weight } & 0.71- & {[95,102]} \\ \text { Feaning and mature weight } & 0.99 & {[95]} \\ \text { Yearling and final weight } & 0.94 & {[95]} \\ \text { Yearling and mature weight } & 0.43 & {[95]}\end{array}$

672 Although genetic correlations estimated in the present study were in favour of the common

673 objectives of genetic improvement programs of Boran cattle in relation to climate change 674 adaptation, it is important to re-estimate the genetic parameters in regular intervals, especially if 675 selection of different traits is made simultaneously [5].

676

677 Summary

678 The Boran cattle is a hardy local cattle breed originated from Borana range lands in the southern 679 Ethiopia and kept for meat and milk production. The breed has special merits of having the ability 680 to survive, produce and reproduce under high ambient temperature, utilize poor quality feed 681 resources, resist water shortage and high diseases incidence including tick infestations. Systematic 682 and meta-analysis in current reviews revealed that Boran cattle employed various adaptation 
683

684

685

686

687

688

689

690

691

692

693

694

695

696

697

698

699

700

701

702

703

704

705

706

707

708

709

710

711

responses (morphological, physiological, biochemical, metabolic, cellular and molecular responses) to cope with harsh environmental conditions inclduing climate change, rangeland degradation, seasonal feed and water shortages and high incidences of tropical endemic diseases.

The meta-analysis using a random-effects model allowed provision of pooled estimates of heritability and genetic correlations for reproduction and production traits, which could be used to solve genetic prediction equations under a population level in purebred Boran cattle. In addition, heritability and genetic-correlation estimates found in the present study suggest that there is high genetic variability for most traits in Boran cattle, and that genetic progress is possible for all studied traits in this breed. The Boran cattle have relatively better reproduction, production and adaption potentials as compared to other indigenous zebu cattle breeds in Ethiopia in arid and semiarid rangelands. On the other hand, the Ethiopian Boran cattle breed is under threat due to several factors such as recurrent drought, pasture deterioration, lack of systematic selection and breeding programs and threat from genetic dilution due to the admixture of other breeds. Thus, we recommend strategic selection and genetic conservation program of Boran cattle breed based on the trait preferances of the Borana pastoralists through proper quantification of important traits and estimation of the pure Boran cattle population for maximum utilization of adapataion and production pottential of this breed.

\section{Acknowledgements}

This study was conducted in the framework of the German-Ethiopian SDG Graduate School "Climate Change Effects on Food Security" (CLIFOOD) between the Food Security Centre, University of Hohenheim (Germany) and the Hawassa University (Ethiopia). The German Academic Exchange Service (DAAD) and the Federal Ministry for Economic Cooperation and Development (BMZ) financed the research under CLIFOOD.

\section{Conflicts of interest}

There are no conflicts of interest for the preparation of this manuscript.

\section{References}


1. Abdurehman, A., 2019. Physiological and anatomical adaptation characteristics of Borana cattle to pastoralist lowland environments. Asian J. Biol. Sci., 12: 364-372.

2. Zander, K.K., A.G. Drucker, A.G. and Holm-Muller, K., 2009.Costing the conservation of animal genetic resources:The case of Borana cattle in Ethiopia and Kenya, Journal of Arid Environments 73 (2009) 550-556

3. Mwai, O., Hanotte, O., Kwon, Y. \& Cho, S., 2015. African Indigenous cattle: Unique genetic resources in a rapidly changing world. Asian Australas. J. Anim. Sci. 28, 911-921.

4. DAGRIS (Domestic Animal Genetic Resources Information System). 2010. Domestic Animal Genetic Resources Information System: http://dagris.ilri.cgiar.org

5. Haile, A., W. Ayalew, N. Kebede, T. Dessie and A. Tegegne, 2011. Breeding strategy to improve Ethiopian Boran cattle for meat and milk production. IPMS (Improving Productivity and Market Success) of Ethiopian Farmers Project Working Paper 26, ILRI., Nairobi, Kenya.

6. Hagos, B., 2016. Ethiopian cattle genetic resources and unique characteristics under a rapidly changing production environment. A review. International Journal of Science and Research, 6(12):1959-1968.

7. Assefa, A., and Hailu, A., 2018. Ethiopian indigenous cattle breed's diversity, distribution, purpose of keeping, and their potential threats. J.Bio. Inno. 7 (5): 770 -789, ISSN 2277-8330

8. Trial, J.C.M., K.E. Gregory, Durkin, J. and Standford, J., 1984. Crossbreeding cattle in beef production programmes in Kenya. II. Comparison of purebred Boran and Boran crossed with the Red Poll and santagertrudis breeds. Trop. Anim. Health Prod., 16: 191-200.

9. Moher D., Liberati A, Tetzlaff, J., Altman, D.G., 2009. Preferred Reporting Items for Systematic Reviews and Meta-Analyses (The PRISMA Group): The PRISMA Statement. PLoS Med 6(7): e1000097, 2009. doi:10.1371/journal. pmed1000097

10. Basu, A., 2017. How to conduct meta-analysis: A Basic Tutorial. University of Cantherbury, open access, http//doi.oer/10.7287/peerj.preprints.2978v1/

11. Sutton, A.J., Abrams, K.R., Jones, D.R., Sheldon, T.A., Song, F., 2000. 'Methods for meta-analysis in medical research.' (Wiley: Chichester, UK)

12. Borenstein, M., Hedges, L.V., Higgins, J., and Rothstein, H.R., 2009. Random effects model. In 'Introduction to meta-analysis'. pp. 69-75. (Wiley:Chichester, UK). 
13. Teel, R.G.D., Torrie, J.H., 1960. 'Principles and procedures of statistics.' (McGraw-Hill Book Company: New York, NY)

14. Zarkovich, S., 1979. Stability of variance patterns.Jomal da Sociedade Indiana de EstatísticasAgrícolas31, 23-48.

15. R Core Team. 2016. 'R: a language and environment for statistical computing.' (R Foundation for Statistical Computing: Vienna)

16. Viechtbauer, W., 2010. Conducting meta-analyses in $\mathrm{R}$ with the metaphor package.Journal of Statistical Software 3,1-48.

17. Higgins, J.P., Thompson, S.G., Deeks, J.J., Altman, D.G. 2003. Measuring inconsistency in meta-analyses.BMJ (Clinical Research Ed.) 327, 557-560. doi:10.1136/bmj.327.7414.557.

18. Cochran, W.G. 1954. The combination of estimates from different experiments.Biometrics 10,101-129.doi:10.2307/3001666.

19. Mirkena, T., Duguma, G., Haile, A., Tibbo, M., Okeyo, A.M., Wurzinger, M. \&Sölkner, J., 2010. Genetics of adaptation in domestic farm animals: A review. Livest.Sci. 132, 112.

20. Mekuriaw, G., and Kebede, A., 2015. A Review on indigenous cattle genetic resources in Ethiopia: Adaptation, status and survival. Online Journal of Animal and Feed Research, 5(5):126-137. ISSN 2228-7701.

21. Renaudeau, D., Collin, A., Yahav, S., de Basilio, V., Gourdine, J.L. and Collier, R.J., 2012. Adaptation to hot climate and strategies to alleviate heat stress in livestock production. Animal 6, 707-728.

22. Bahbahani, H. \&Hanotte, O., 2015. Genetic resistance-tolerance to vector-borne diseases, prospect and challenges of genomics. OIE Scientific and Technical Review, 34,185-197

23. Mota, R.R., Tempelman, R.J., Lopes, P.S., Aguilar, I., Silva, F.F. \& Cardoso, F.F., $2016 b$. Genotype by environment interaction for tick resistance of Hereford and Braford beef cattle using reaction norm models.Genet. Sel. Evol. 48, 3. 
24. Hanotte, O., Ronin, Y., Agaba, M., Nilsson, P., Gelhaus, A., Horstmann, R., Sugimoto, Y., Kemp, S., Gibson, J., Korol, A. \&Soller, M., 2003. Mapping of quantitative trait loci controlling trypanotolerance in a cross of tolerant West African N'Dama and susceptible East African Boran cattle. Proceedings of the National Academy of Sciences, 100, 7443-7448.

25. Degefa, T.2016. Ovarian follicular dynamics, super-ovulatory response, and in vivo embryo production potential of Boran (Bosindicus) and Boran *Holstein cross cattle in Ethiopia.PhD. Dissertation, FVM, Addis Ababa University, pp.93

26. Sejain A.P., Amitha, J.P., Rashamol, V.P., Vandana, G.D., and Savitha, S.T., 2018. Climate Change and Cattle Production: Impact and Adaptation. J Vet Med Res 5(4): 1134.

27. Mahgoub, O., Kadim, I.T., Al-Dhahab, A., Bello, R.B., Al-Amri, I.S., Ali, A.A.A., and Khalaf, S., 2010. An assessment of Omani native sheep fin a production and quality characteristics. Journal of Agricultural and Marine Sciences 15, 9-14.

28. McManus, C.M., Paludo, G.R., Louvandini, H., Gugel, R., Sasaki, L.C.B., and Paiva, S.R., 2009. Heat tolerance in Brazilian sheep: physiological and blood parameters. Tropical Animal Health Production 41, 95-101.

29. Phillips, L., 2012. The East African Boran-'the World's hardiest breed'. Farmer's Weekly, November 2, 2012. https://www.farmersweekly.co.za/animals/cattle/the-east-africanboranthe-worlds-hardiest-breed/php/hardiness/Physiol. Behav., 70: 391-396.

30. Jian, W., Ke, Y., and Cheng, L., 2016. Physiological responses and lactation to cutaneous evaporative heat loss in Bosindicus, Bostaurus, and their crossbreds.Asian-Australasian Journal of Animal Sciences 28, 1558-1564.

31. Tao, S., and Dahl, G.E., Heat stress effects during late gestation on dry cows and their calves. J Dairy Sci. 2013; 96: 4079-4093.

32. Lacetera, N, Bernabucci, U, Ronchi, B and Nardone, A 1996. Body condition score, metabolic status and milk production of early lactating dairy cows exposed to warm environment. Rivista di AgricolturaSubtropicale e tropicale 90, 43-55. 
33. Farooq, U., Samad, H.A., Shehzad, F., and Qayyum, A., 2010. Physiological responses of cattle to heat stress. World Applied Sci. J., 8: 38-43.

34. Australian Small Boran Inc., 2018. Hardiness and adaptability of boran cattle.http://www.austsmallboran.com.au/index.

35. Ratnakaran, A.P., Sejian, V., Sanjo Jose, V., Vaswani, S., Bagath, M., 2017. Behavioral responses to livestock adaptation to heat stress challenges. Asian J Anim Sci. 11: 1-3.

36. Jung, J., Yngvesson, J. \& Jensen, P., 2002. Effects of reduced time on pasture caused by prolonged walking on behaviour and production of Mpwapwa Zebu cattle. Blackwell Science Ltd. Grass and Forage Sci. 57, 105-112.

37. Huber, R., Baumung, R., Mwai, O., Semambo, D., Winckler, C. \&Wurzinger, M., 2007. Grazing, social and comfort behaviour of Ankole and crossbred (Ankole x Holstein) heifers on pasture in south western Uganda. Appl. Anim. Behav. Sci. 112, 223-234.

38. Butt, B., 2010. Seasonal space-time dynamics of cattle behavior and mobility among Maasai Pastoralists in semi-arid Kenya. J. Arid Environ. 74, 403-413.

39. Räisänen, S., 2015. Grazing behavior of Ankole and Boran cattle in an improved herding production system. Department of Animal Environment and Health, Swedish University of Agricultural Sciences, ISSN 1652-280X

40. Valente, É.E.L., Chizzotti, M.L., Oliveira, C.V.R, Galvão, M.C., Domingues SS, Rodrigues, A.C. and Ladeira, M.M., 2015. Intake, physiological parameters and behavior of Angus and Nellore bulls subjected to heat stress. Semina: CiênciasAgrárias 36, 4565-4574.

41. Shilja, S., Sejian, V., Bagath, M., Mech, A., David, C.G., Kurien, E.K., Varma, G., and Bhatta, R., 2016. Adaptive capability as indicated by behavioural and physiological responses, plasma HSP70 level, and PBMC HSP70 mRNA expression in Osmanabadi goats subjected to combined (heat and nutritional) stressors. International Journal of Biometeorology 60, 13111323. 
42. Chedid, M., Jaber, L.S., Giger-Reverdin, S., Duvaux-Ponter, C., and Hamadeh, S.K., 2014. Water stress in sheep raised under arid conditions, Canadian Journal of Animal Science 94, 243-257.

43. Darcan, N., Cedden, F., and Cankaya, S., 2008. Spraying effects on some physiological and behavioural traits of goats in a subtropical climate. Italian Journal of Animal Science 7, 77-85.

44. Provolo, G., and Riva, E., 2009. One-year study of lying and standing behavior of dairy cows in a free stall barn in Italy. Journal of Agricultural Engineering 40, 27-33.

45. Blackshaw, J.K., and Blackshaw, A.W., 1994. Heat stress in cattle and the effect of shade on production and behaviour: A review. Aust. J. Exp. Agric., 34: 285-295.

46. Hooda, O.K., and Upadhyay, R.C., 2014. Physiological responses, growth rate and blood metabolites under feed restriction and thermal exposure in kids. Journal of Stress Physiology and Biochemistry 10, 214-227.

47. Tolera, A., and Abebe, A., 2007. Livestock production in pastoral and agro-pastoral production systems of Southern Ethiopia.Livest.Res. Rural Dev., Vol. 19, No. 12.

48. Oba, G., E. Post, P., Syvertsen, P.O., and Stenseth, N.C., 2000. Bush cover and range condition assessments in relation to landscape and grazing in Southern Ethiopia. Landscape Ecol., 15: 535-546.

49. Dalle, G., Maass, B.L., and Isselstein, J., 2006. Encroachment of woody plants and its impact on pastoral livestock production in the Borana lowlands, Southern Oromia, Ethiopia. Afr. J. Ecol., 44: 237-246.

50. Nardone, A., Ronchi, B., Lacetera, N., Ranieri, M.S., and Bernabucci, U., 2010. Effects of climate change on animal production and sustainability of livestock systems. Livestock Science 130, 57-69.

51. Megersa, B., Markemann, A., Angassa, A., Ogutu, J.A., Piepho, H.P., and Zarate,A.V., 2014. Livestock diversification: An adaptive strategy to climate and rangeland ecosystem changes in Southern Ethiopia. Hum. Ecol., 42: 509-520. 
52. Bradley, D.G., MacHugh, D.E., Cunningham, P., and Loftus, R.T., 1996. Mitochondrial diversity and the origins of African and European cattle.Proc.Natl.Acad.Sci. USA.

53. Binsiya, T.K., Sejian. V., Bagath, M., Krishnan, G., Hyder, I., and Manimaran, A., 2017. Significance of hypothalamic-pituitary-adrenal axis to adapt to climate change in livestock.Int Res J Agri Food Sci. 2: 1-20

54. Marina, L.P., and von Keyserlingk, A.G., 2017. Invited review: Effects of heat stress on dairy cattle welfare. Journal of Dairy Science 100, 8645-8657.

55. Wojtas K, Cwynar P and Kolacz, R., 2014. Effect of thermal stress on physiological and blood parameters in merino sheep. Bulletin of the Veterinary Institute in Pulawy 58, 283-288.

56. Kaliber, M., Koluman, N., and Silanikove, N., 2016. Physiological and behavioral basis for the successful adaptation of goats to severe water restriction under hot environmental conditions. Animal 10, 82-88.

57. Haque, N., Ludri, A., Hossain, S.A. and Ashutosh, M., 2013. Impact on hematological parameters in young and adult Murrah buffaloes exposed to acute heat stress. Buffalo Bulletin 3, 321-326.

58. Chaudhary, S.S., Singh, V.K., Upadhyay, R.C., Pur, i G., Odedara, A.B., and Patel, P.A., 2015. Evaluation of physiological and biochemical responses in different seasons in Surti buffaloes. Veterinary World 8, 727-731.

59. Aleena, J., Pragna, P., Archana, P.R., Sejian, V., Bagath, M., Krishnan, G., Manimaran, A., Beena, V., Kurien, E.K., Varma, G., and Bhatta, R. 2016. Significance of metabolic response in livestock for adapting to heat stress challenges. Asian Journal of Animal Sciences $10,224-234$.

60. Alberghina, D., Piccione, G., Casella, S., Panzera, M., Morgante, M., and Gianesella, M., 2013. The effect of the season on some blood metabolites and haptoglobin in dairy cows during postpartum period. Archives Animal Breeding 56, 354-359.

61. Khalek, T.M.M.A., 2007. Thermoregulatory responses of sheep to starvation and heat stress conditions. Egyptian Journal of Animal Production 44, 137-150. 
62. Gupta, M., Kumar, S., Dangi, S.S., and Jangir, B.L., 2013. Physiological, biochemical and molecular responses to thermal stress in goats. International Journal of Livestock Research 3, $27-38$.

63. Zhang, H., Yin, M., Huang, L., Wang, J., Gong, L., Liu, J., and Sun, B., 2017. Evaluation of the cellular and animal models for the study of antioxidant activity: a review. Journal of Food Science 82, 278-288.

64. Pragna, P., Sejian, V., Soren, N.M., Bagath, M., Krishnan, G., Beena, V., Devi, P.I., and Bhatta, R., 2018. Summer season induced rhythmic alterations in metabolic activities to adapt to heat stress in three indigenous (Osmanabadi, Malabari and Salem Black) goat breeds. Biological Rhythm Research 49, 551-565.

65. Todini, L., 2007. Thyroid hormones in small ruminants: effects of endogenous, environmental and nutritional factors. Animal 1, 997-1008.

66. Pereira, A.M., Baccari, F., Titto, E.A. and Almeida, J.A., 2008. Effect of thermal stress on physiological parameters, feed intake and plasma thyroid hormones concentration in Alentejana, Mertolenga, Frisian and Limousine cattle breeds. International Journal of Biometeorology 52, 199-208.

67. Nazifi, S., Saeb, M., Rowghani, E., and Kaveh, K., 2003. The influences of thermal stress on serum biochemical parameters of Iranian fat-tailed sheep and their correlation with triiodothyronine (T3), thyroxine (T4) and cortisol concentrations. Comparative Clinical Pathology 12, 135-139.

68. Banerjee D, Upadhyay RC, Chaudhary UB, Kumar R, Singh S, Ashutosh, Das TK and De S 2015. Seasonal variations in physio-biochemical profiles of Indian goats in the paradigm of hot and cold climate. Biological Rhythm Research 46, 221-236.

69. Baumgard, L.H., and Rhoads, R.P., 2012. Ruminant nutrition symposium: ruminant production and metabolic responses to heat stress. Journal of Animal Science 90, 1855-1865. 70. Shehab-El-Deen, M.A., Leroy, J.L., Fadel, M.S., Saleh, S.Y., Maes, D., and Van Soom, A. 2010. Biochemical changes in the follicular fluid of the dominant follicle of high producing 
dairy cows exposed to heat stress early post-partum. Animal Reproduction Science 117, 189200.

71. Higashikubo, R., White, R.A., and Roti, J.L., 1993. Flow cytometricBrdUrdpulsechase study of heat induced cellcycle progression delays. Cell Proliferation 26, 337-348.

72. Slimen, B., Najar, T., Ghram, A., and Abdrrabba, M., 2016. Heat stress effects on livestock: molecular, cellular and metabolic aspects, a review. Journal of Animal Physiology and Animal Nutrition 100, 401-412.

73. Hao, Y., Feng, Y., Yang, P., Cui, Y., Liu, J., Yang, C. and Gu, X., 2016. Transcriptome analysis reveals that constant heat stress modifies the metabolism and structure of the porcine Longissimusdorsi skeletal muscle. Molecular Genetics and Genomics 291, e2101-2115.

74. Zander, K., 2011. Attitudes of Livestock Keepers to Breeding Strategies - Threats and 10.doi:10.5539/jas.v3n2p3

75. Mekonen, T., 2018. Characterization of productive and reproductive performances, 913 morphometric and challenges and opportunities of indigenous cattle breeds of Ethiopia: A review. International Journal of Livestock Production.9(3):29-41. lactating Holstein cows: I. Production, metabolism, and aspects of circulating somatotropin. Journal of Dairy Science 92, 1986-1997.

77. Archana, P.R., Sejian, V., Ruban, W., Bagath, M., Krishnan, G., Aleena, J., Manjunathareddy, G.B., Beena, V., and Bhatta, R., 2018. Comparative assessment of heat stress induced changes in carcass traits, plasma leptin profile and skeletal muscle myostatin and HSP70 gene expression patterns between indigenous Osmanabadi and Salem Black goat breeds. Meat Science 141, 66-80. 
78. Rojas-Downing, M.M., Nejadhashem, A.P., Harrigan, T. and Woznicki, S.A., 2017. Climate change and livestock: impacts, adaptation, and mitigation. Climate Risk Management $16,145-163$.

79. De Oliveira, H.R., Ventura, H T, , Costa ,E.V., Pereira, M.A., Veroneze, R., Duarte, M.S., Gomes, O.H., de Siqueira, B. D., and De Silva, F.F., 2017. Meta-analysis of geneticparameter estimates for reproduction, growth and carcass traits in Nellore cattle by using a random-effects model.Animal Production Science. CISRO publication http://dx.doi.org/10.1071/AN16712, https://www.researchgate.net/publication/317136429

80. Bax, L., Ikeda, N., Fukui, N., Yaju, Y., Tsuruta, H., and Moons, K.G., 2009. More than numbers: the power of graphs in meta-analysis. American Journal of Epidemiology 169, 249255. doi:10.1093/aje/kwn340.

81. Akanno, E., Schenkel, F., Quinton, V., Friendship, R., and Robinson, J., 2013. Metaanalysis of genetic parameter estimates for reproduction, growth and carcass traits of pigs in the tropics. Livestock Science 152, 101-113. doi:10.1016/j.livsci.2012.07.021.

82. Diaz, I., Crews, D., Enns, R., 2014. Cluster and meta-analyses of genetic parameters for feed intake traits in growing beef cattle. Journal of Animal Breeding and Genetics 131, 217226. doi:10.1111/jbg.12063.

83. Demeke, S., Neser, F.W.C. \&Schoeman, S.J., 2004. Estimates of genetic parameters for Boran, Friesian, and crosses of Friesian and Jersey with the Boran cattle in the tropical highlands of Ethiopia: reproduction traits. J. Anim. Breed. Genet. 121, 57-65.

84. Yifat D, Bahilibi W, and Desie S.,2012. Reproductive Performance of Boran Cows at Tatesa Cattle Breeding Center. Adv. Biol. Res. 6(3):101-105.

85. Bayou, E., Haile, A., Gizaw, S., Mekasha, Y., 2015.Evaluation of non-genetic factors affecting calf growth, reproductive performance, and milk production of traditionally managed Sheko cattle in South West Ethiopia.Springer Plus, 4(5):68-93. 

reared at two Feedlots of southern Ethiopia, using linear and curvefit Regressions equations. Wayamba Journal of Animal Science, 1467 - P1474, ISSN 1479801685

87. Rege, J.E.O., Hanotte, O., Mamo, Y., Asrat, B. \&Dessie, T., 2007. Domestic Animal Genetic Resources Information System (DAGRIS). Addis Ababa, Ethiopia: International Livestock Research Institute.

955

956

957

88. Patterson, D.J., Cooke, R.F., Dahlke, G.R., Funston, R.N., Hall, J.B., Lamb, G.C., Lauderdale, J., Perry, G.A. \& Van Eenennaam, A.L., 2016. 1168 Physiological and management advances enhancing adoption of applied reproductive management procedures in beef cattle. J. Anim. Sci. 94, 560-561.

89. Coppock, D.L., 1994.The Boran Plateau of Southern Ethiopia: Synthesis of pastoral research, development and change, 1980-91. ILCA Systems Study, International Livestock Centre for Africa, Addis Ababa, Ethiopia.

90. Haile-Mariam, M., Malmfors, B., and Philipsson, J., 2010. BORAN: Indigenous African cattle with potential. https://www. netwerk24.com/landbou/Argief/boran-indigenousafricancattle-with-potential-20191019.

91. Berry, D., Wall, E., and Pryce, J., 2014. Genetics and genomics of reproductive performance in dairy and beef cattle.Animal 8, 105-121. doi:10.1017/S1751731114000743

92. Corbet, N.J., Shepherd, R.K., Burrow, H.M., Prayaga, K.C., Van der Westhuizen, J. \&Bosman, D.J., 2006. Evaluation of Bonsmara and Belmont Red cattle breeds in South Africa. 2. Genetic parameters for growth and fertility. Aust. J. Exp. Agri. 46, 213-223.

93. Giannotti, J.D.G., Packer, I.U., and Mercadante, M.E.Z., 2005. Meta-analysis for heritability of estimates growth traits in beef cattle.RevistaBrasileira de Zootecnia34, 11731180. doi:10.1590/S1516-3598200500040001.

94. Ndofor-Foleng, H.M., Ebangi, A.L., Agu, C.I. \&Okenyi, N., 2012. Estimation of genetic parameters for preweaning and postweaning growth traits in the Gudali beef cattle using multiple trait derivative free restricted maximum likelihood. Afr. J. Biotech. 11,14410-14416. 
95. Neser, F.W.C., Van Wyk, J.B., Fair, M.D. \&Lubout, P., 2012. Genetic evaluation of growth traits in beef cattle using random regression models. S. Afr. J. Anim. Sci. 42, 474-477.

96. Wasike, C.B., Indetie, D., Ojango, J.M.K \&Kahi, A.K., 2009. Direct and maternal (co)variance components and genetic parameters for growth and reproductive traits in the Boran cattle in Kenya. Trop. Anim. Health Prod. 41, 741-748.

97. Nephawe, K.A., 2004. Application of random regression models to the genetic evaluation of cow weight in Bonsmara cattle of South Africa. S. Afr. J. Anim. Sci. 34, 166-173.

98. Bolormaa, S., Pryce, J.E., Kemper, K., Savin, K., Hayes, B.J., Barendse, W., Zhang, Y., Reich, C.M., Mason, B.A., Bunch, R.J. \& Harrison, B.E., 2013. Accuracy of prediction of genomic breeding values for residual feed intake and carcass and meat quality traits in Bostaurus,Bosindicus, and composite beef cattle. J. Anim. Sci. 91, 3088-3104.

99. Nkrumah, J.D., Basarab, J.A., Wang, Z., Li, C., Price, M.A., Okine, E.K., Crews Jr, D.H. \& Moore, S.S., 2007. Genetic and phenotypic relationships of feed intake and measures of efficiency with growth and carcass merit of beef cattle. J. Anim. Sci. 85, 2711-2720.

100. Van der Westhuizen, R.R., Schoeman, S.J., Jordaan, G.F. \& Van der Wyk, J.B., 2001. Genetic parameters for reproductive traits in a beef cattle herd using multitrait analysis. S. Afr. J. Anim. Sci. 31, 4-48.

101. Bosso, N.A., Van der Waaij, E.H., Agyemang, K. \& Van Arendok, J.A.M., 2009. Genetic parameters for growth traits in N'Dama cattle under tsetse challenge in the Gambia. Livest. Res. Rur. Dev. 21, www. Lrrd.org/lrrd21/3/boss21033.htm.

102. Maiwashe, A.N., Bradfield, M.J., Theron, H.E. \& Van Wyk, J.B., 2002. Genetic parameter estimates for body measurements and growth traits in South African Bonsmara cattle. Livest. Prod. Sci. 75, 293-300. 
1 Figure1. Flow diagram of search and selection of studies

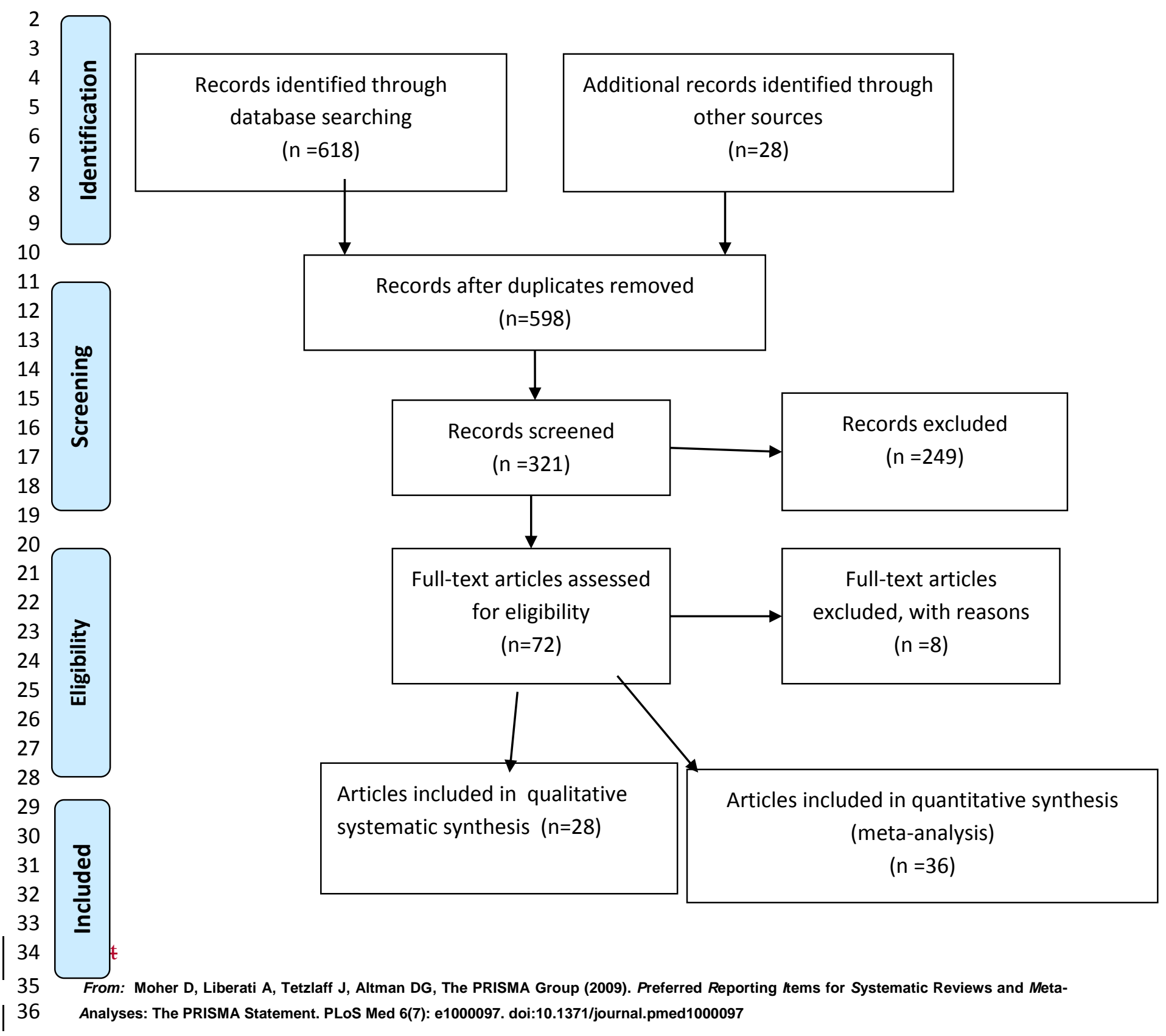




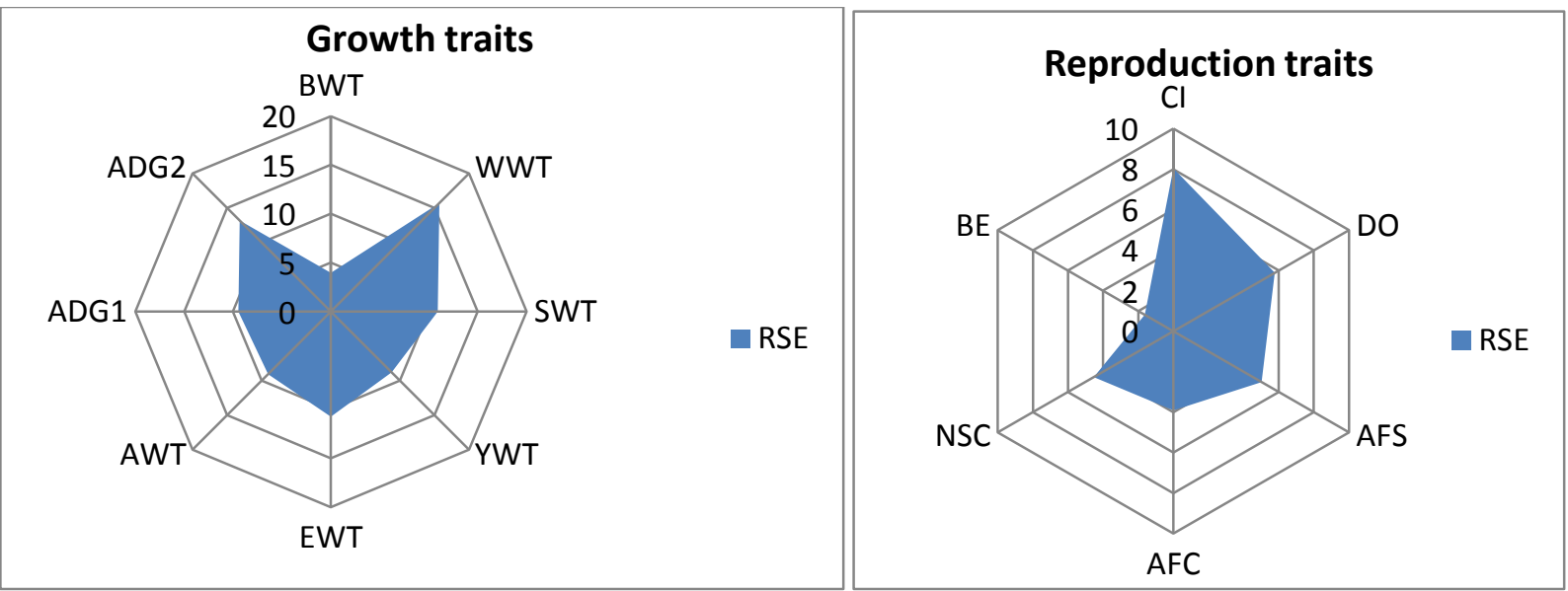

Milk production and composition traits

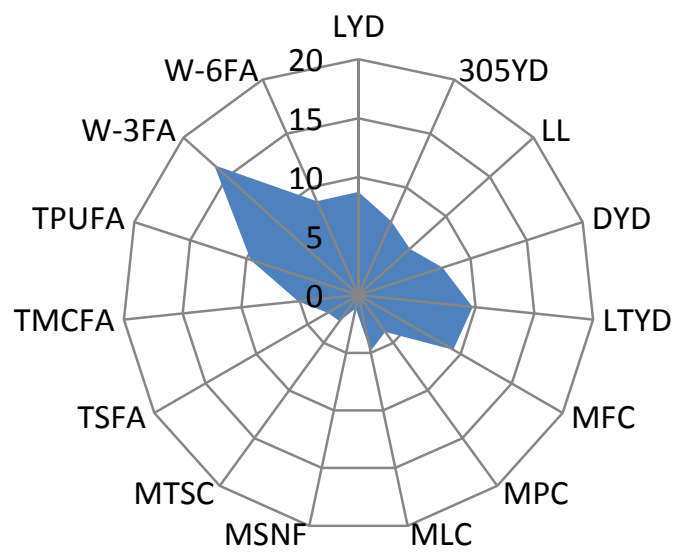

Fig 2. Box plots for Relative standard errors of Production and reproduction traits of 


\section{Click here to access/download Supporting Information \\ PRISMA 2009 checklist.doc}

